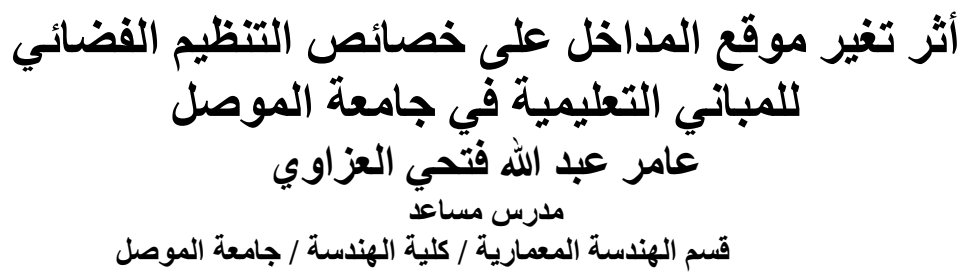

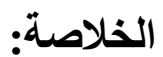

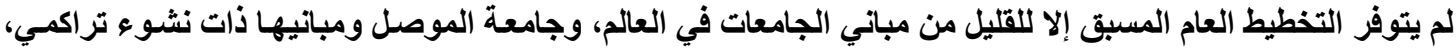

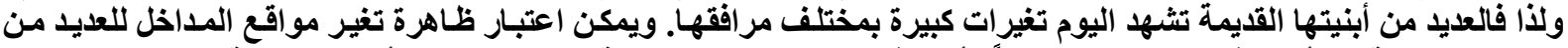

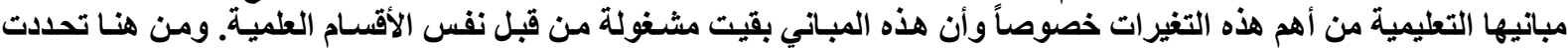

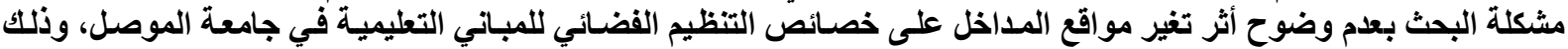

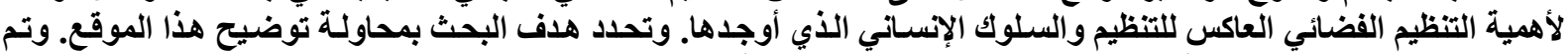

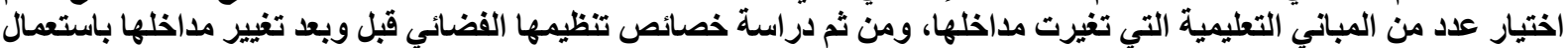

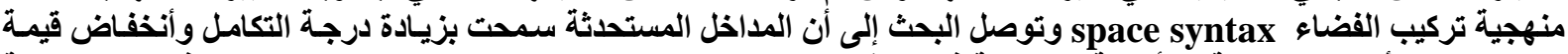

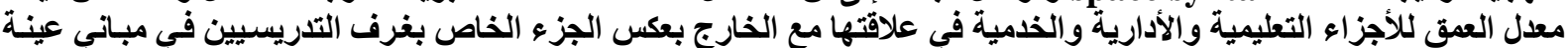

\title{
The Impact of Changing the Entries' Location on the Spatial Configuration Features for the Educational Buildings in the University of Mosul
}

\author{
Amer Abdullah Fathi Al-Azawi \\ Assist. Lecturer \\ Architecture Engineering Department / College of Engineering \\ University of Mosul
}

\begin{abstract}
General pre-planning was available only for some buildings of universities in the world. University of Mosul and its buildings are cumulative development university, therefore, many of its old buildings today witness big changes in various of its utilities, and the phenomenon of changing the entries' location of some of its educational buildings may considered as the most important of these changes especially these building are occupied by the same science departments, hence the research problem is defined, which is the fuzziness of the impact of changing the entries' location on the spatial configuration features for the educational buildings in the university of Mosul, due to the importance of the spatial configuration which reflects the human organizing and behaviour that created this configuration, the research aim was defined as trying to illustrate this impact, and some of educational buildings are chosen, which their entries are changed, then their features of spatial configurations are studied before and after change by using the space syntax methodology.

The research reached at the originated entries allowed to increase integration degree and decreasing the depth rate value for the educational administrative and servant departments in their relation with exterior on the contrary of the particular part of the teaching staff rooms in the research buildings sample.
\end{abstract}

$$
\text { قبل: } 2013 \text { - } 9 \text { - } 23
$$$$
\text { أستلم: } 2013 \text { - 20 - n } 13 \text { - } 13
$$ 


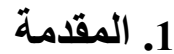

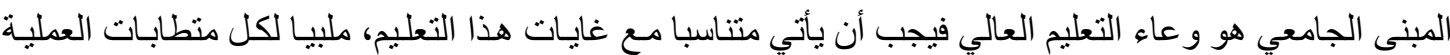

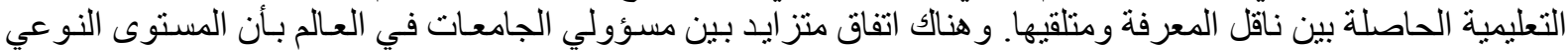

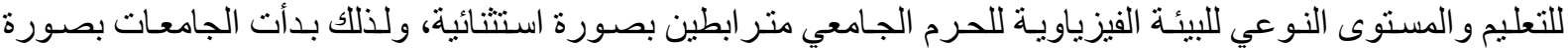

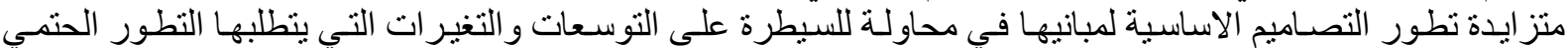

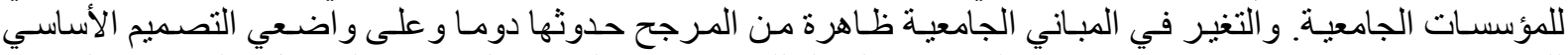

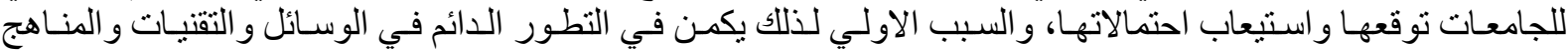

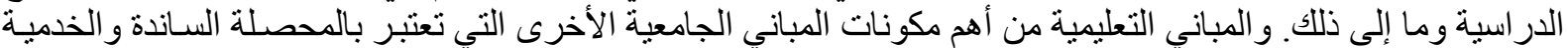

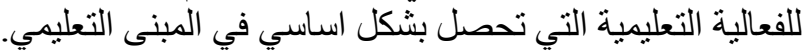

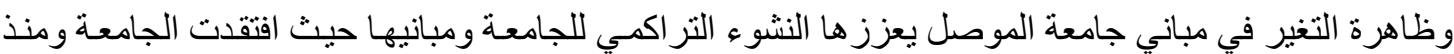

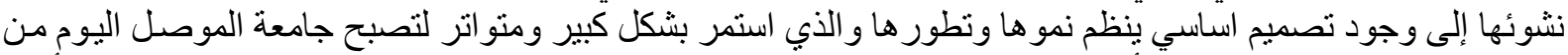

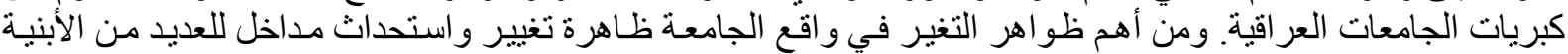

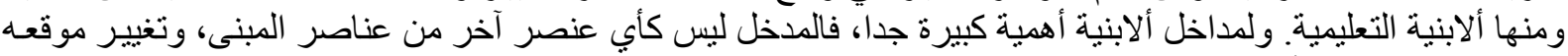

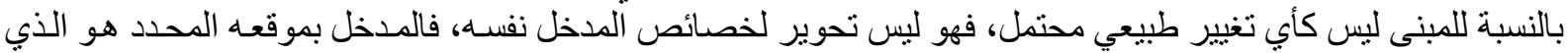

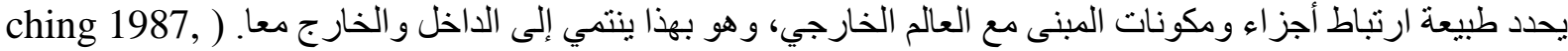

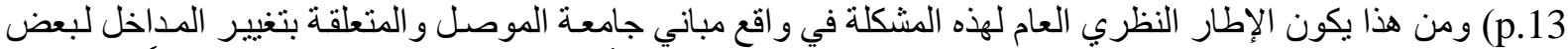

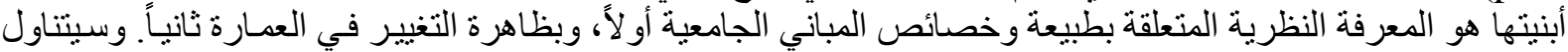

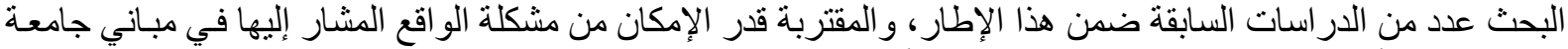

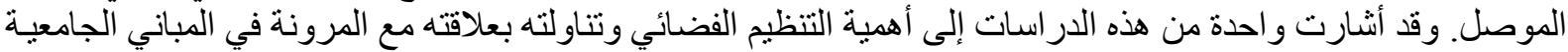

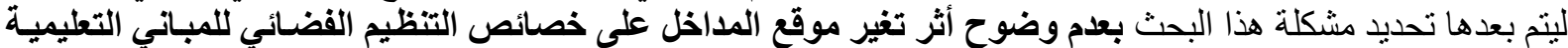

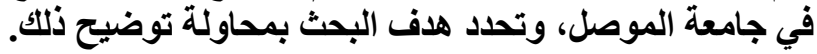

ولتحقيق هدف البحث تم انتخاب عدد من المباني التعليمبة في جامعة الموصل و التي تم فيها تغيير موقع مداخلها،

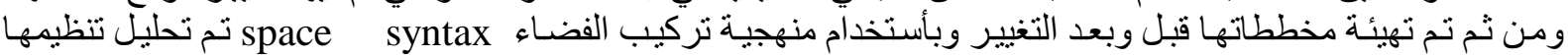
الفضائي الداخلي لحالتيها قبل وبعد تغيير مداخلها في محاولة لبيان آثار هذا التغيير أو لا و لاكتشاف اسبابه ثانيا.

\section{2 المتطلبات التصميمية في المباني الجامعية}

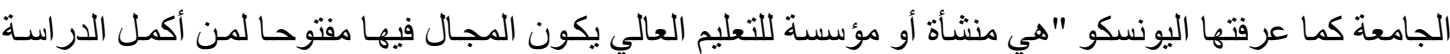

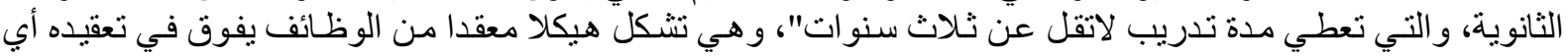

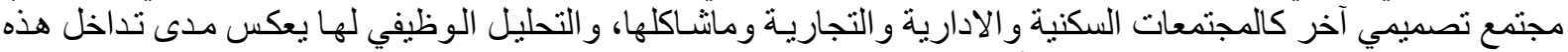

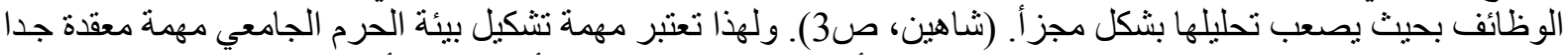

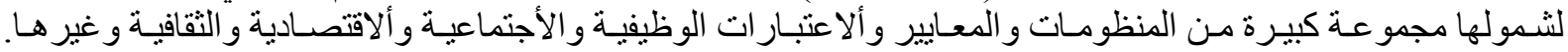

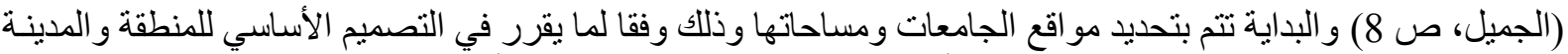

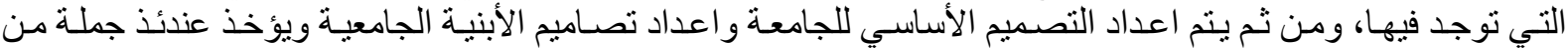

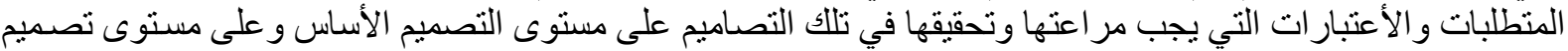

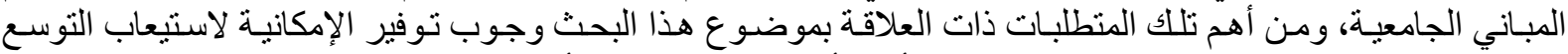

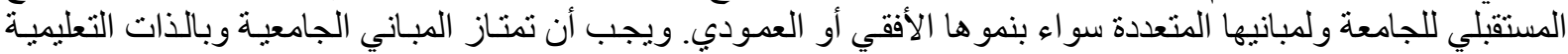

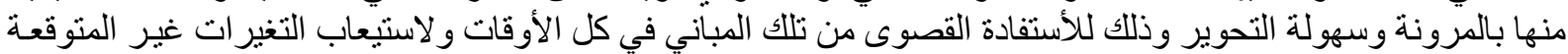

و غير المخطط لها. (شاهين، ص 6-12).

ويعتبر نظام الحركة في المباني الجامعية من أهم القرارات التخطيطية والتصميمية و التي يمكن ان تترتب عليها العديد

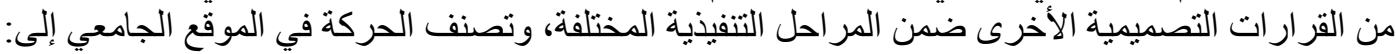

الحركة الخارجية التي يرتبط بها الموقع الجامعي مع شبكة الطرق في المدينـة وذلك عن طريق مداخل الجامعة 
الحركة الداخلية الرئيسية داخل الحرم الجامعي مابين المباني الجامعية المختلفة.

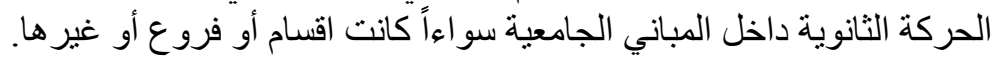

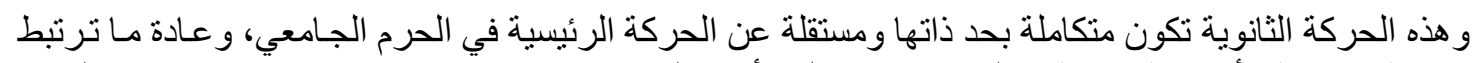

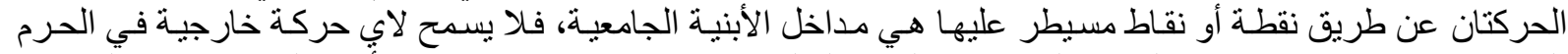

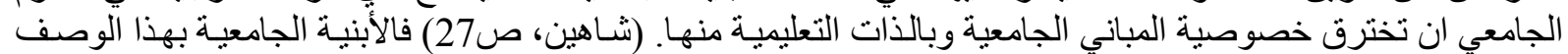

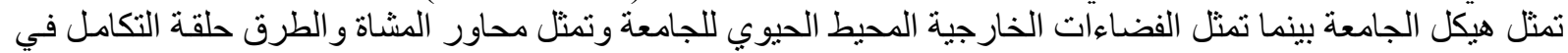

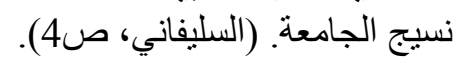

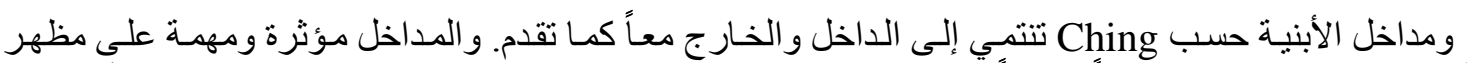

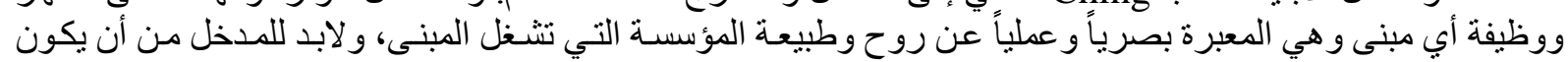

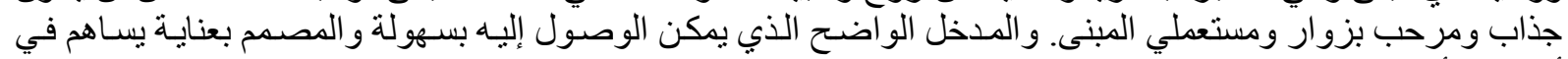

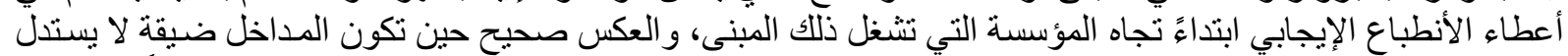

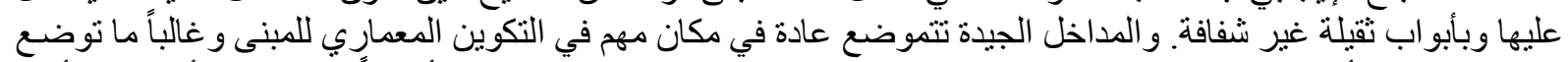

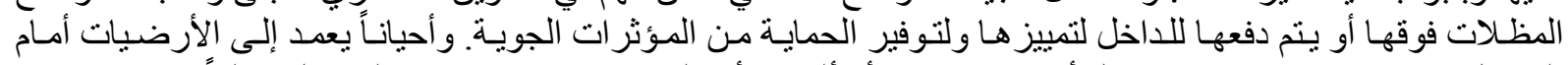

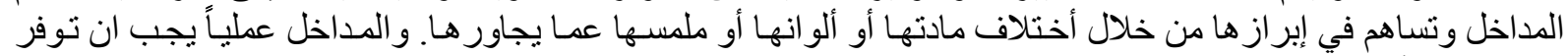

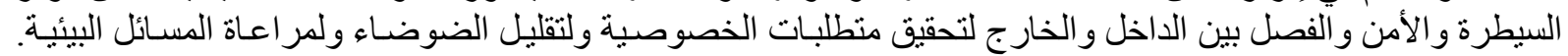

(Booklet, P. 9-11)

\section{3}

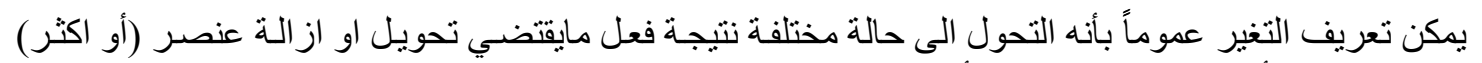

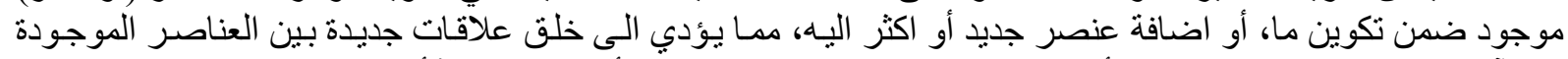

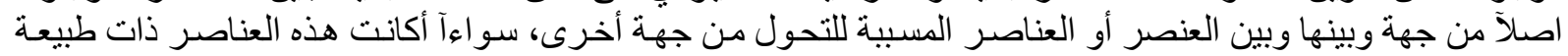

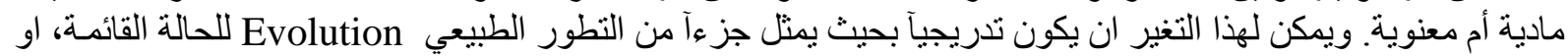

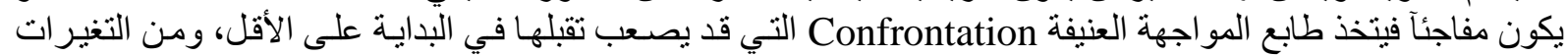

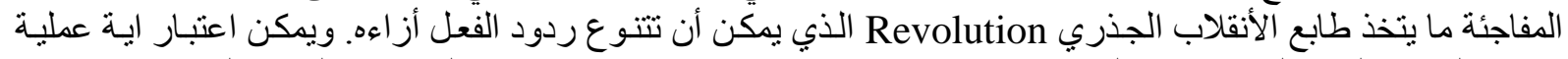

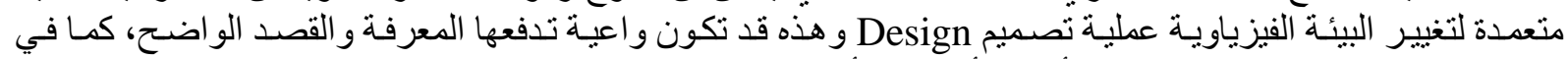

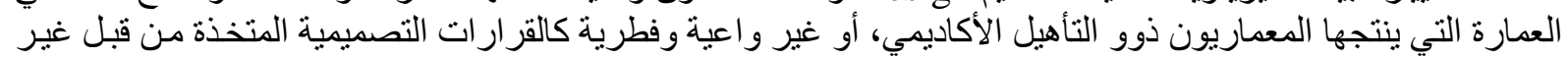

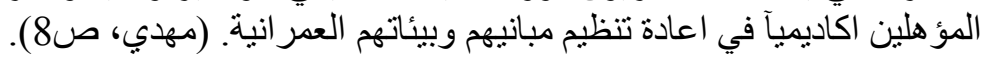

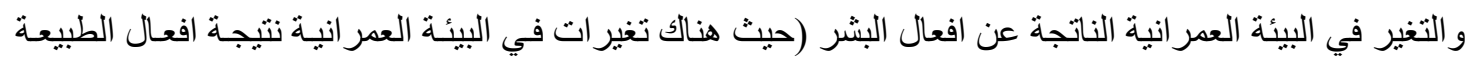

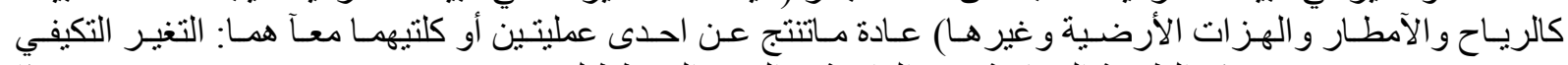
Adaptive Change

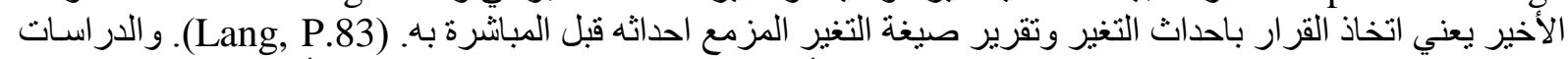

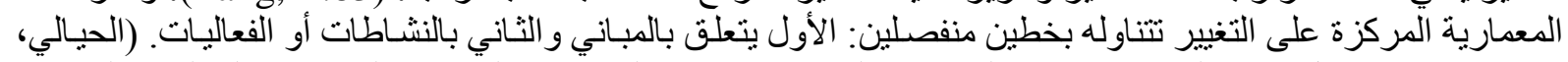

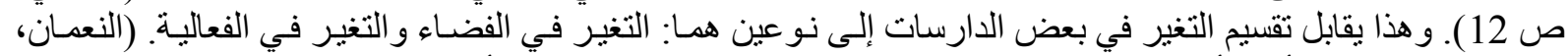
ص 2) ويمكن تحديد أبرز أنماط التغير الحاصلة في البيئات العمر انية الحضرية التية وكالأتي:

- - الملء Infill المتمثل بحشو الفر اغ ضمن سياق حضر في معين.

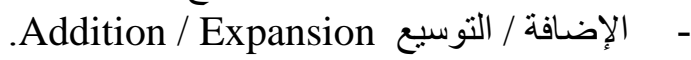
- مeuse - - -

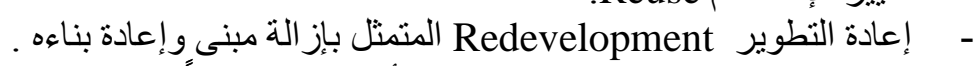

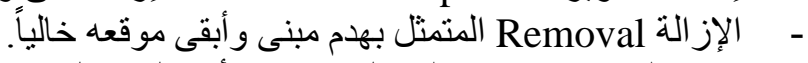

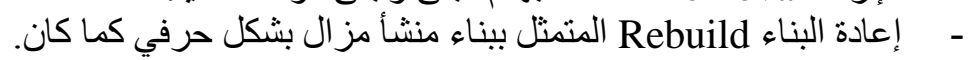

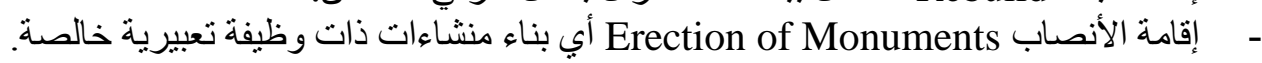


وقد تتداخل وتندمج بعض هذه الأنشطة مع بعضها في نشاط واحد. (مهدي، ص 42). و التغير في المباني أعتماداً على ما تقدم يمكن أن يتم تتاوله عبر مايلي:

مبنى و احد يتم التغير فيه لمرة واحدة أو لعدة مرات، وهنـا الكلام يكون عن المرونـة وسـهولة التحويل واستيعاب

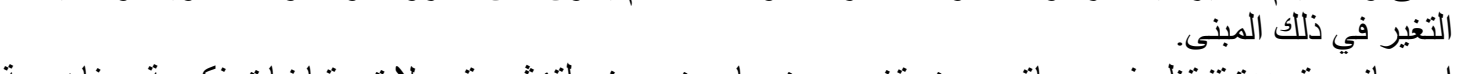
او مبـاني متعددة تنتظم في سياق معين يتغيـر بعضـها عـن بعض لتؤشـر تحو لات وتباينـات فكريـة ومفاهيميـة وطرزية (أسلوبية).

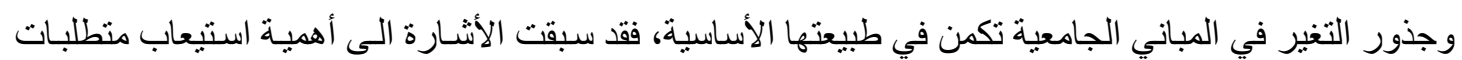

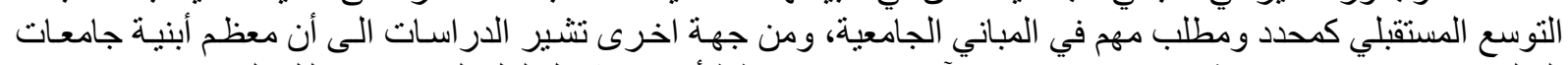

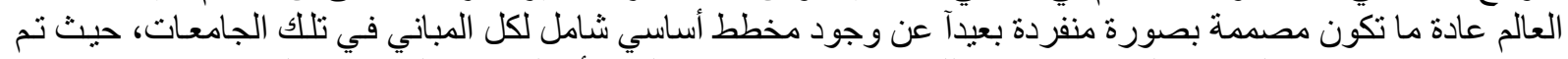

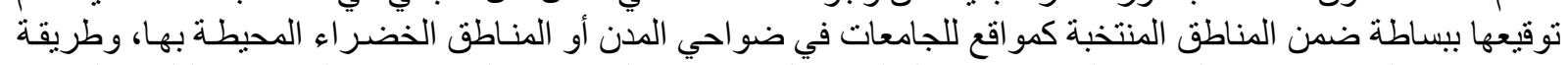

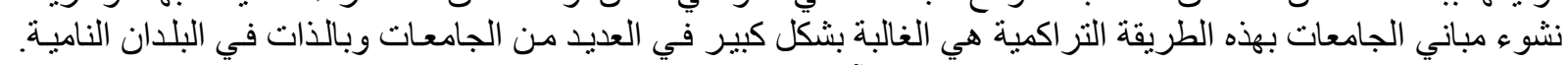

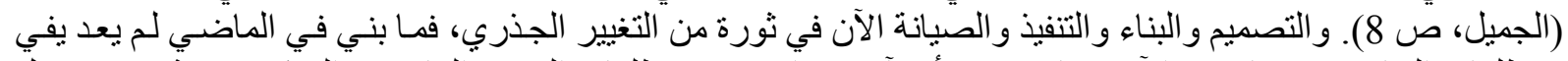

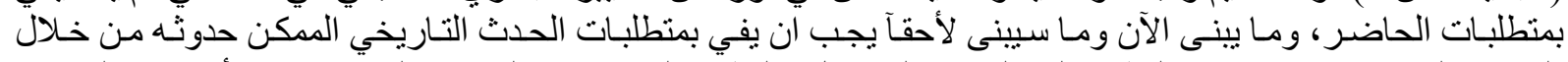

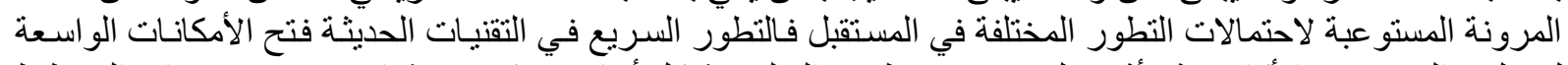

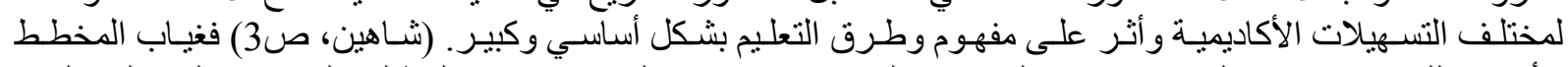

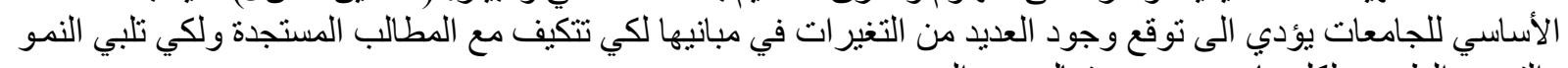

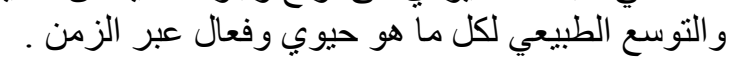

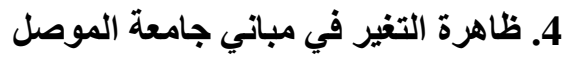

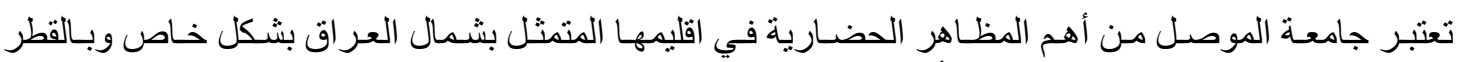

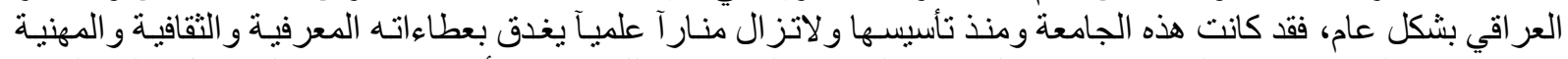

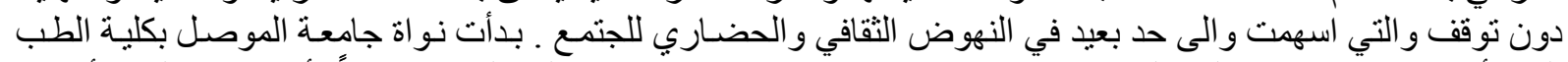

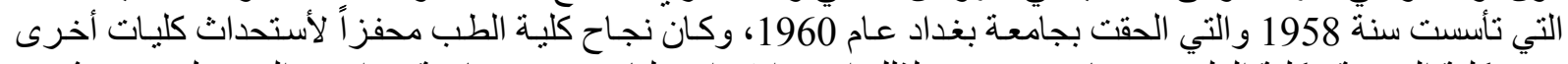

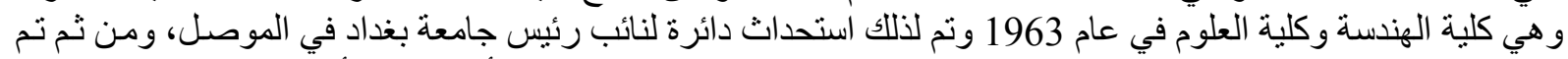

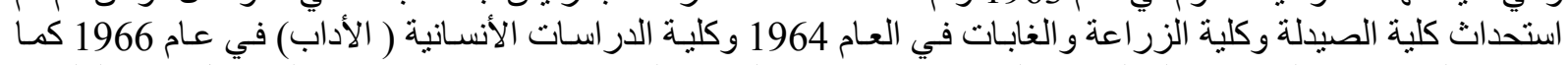

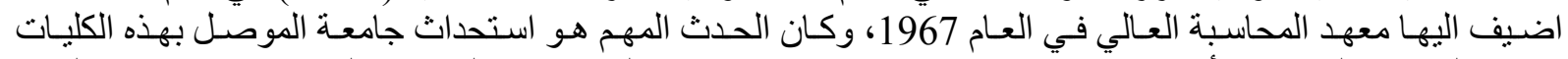

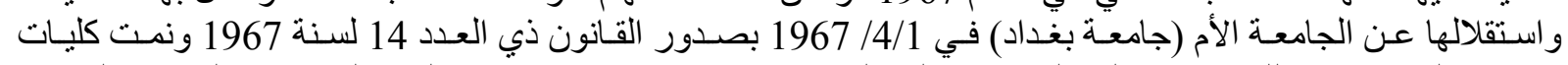

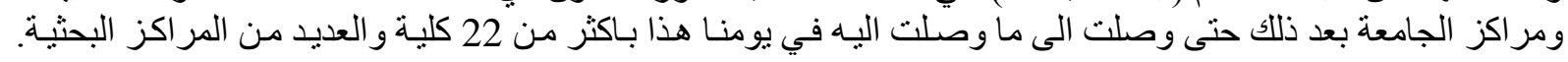

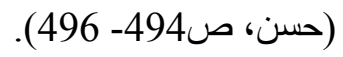

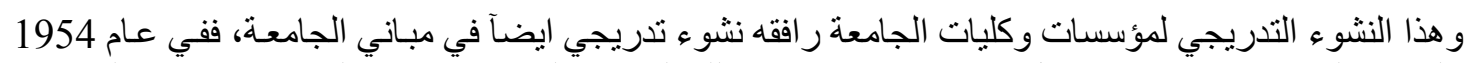

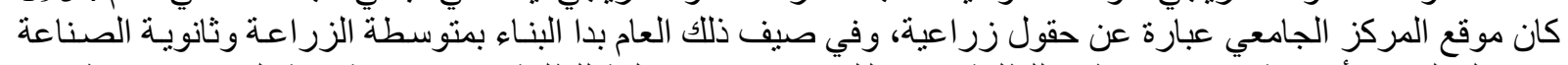

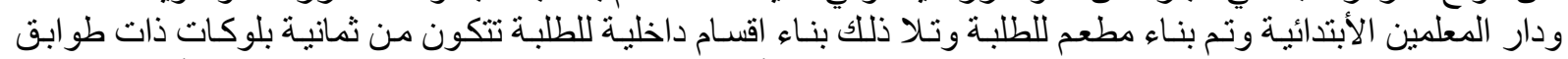

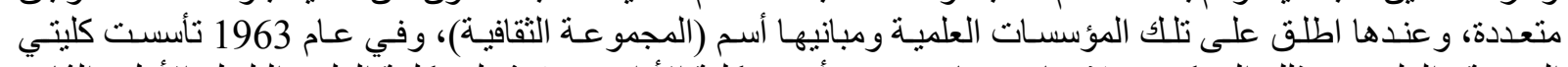

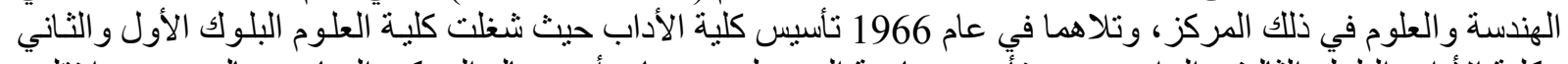

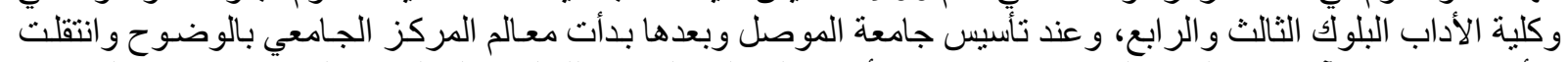

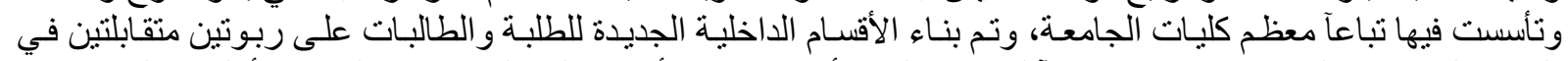

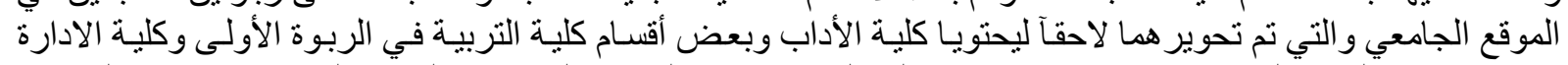

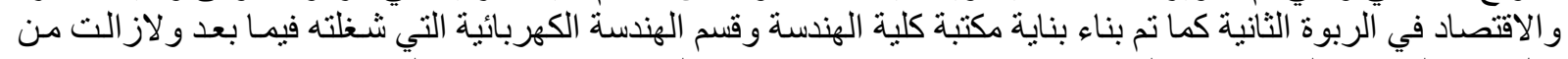

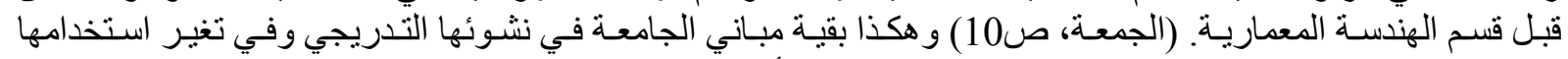

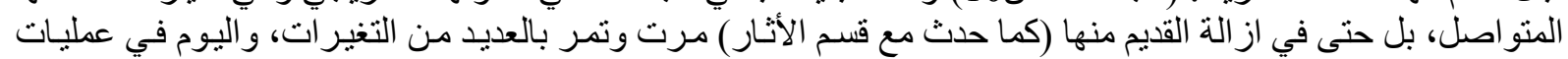

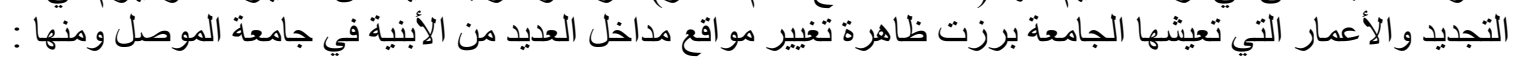




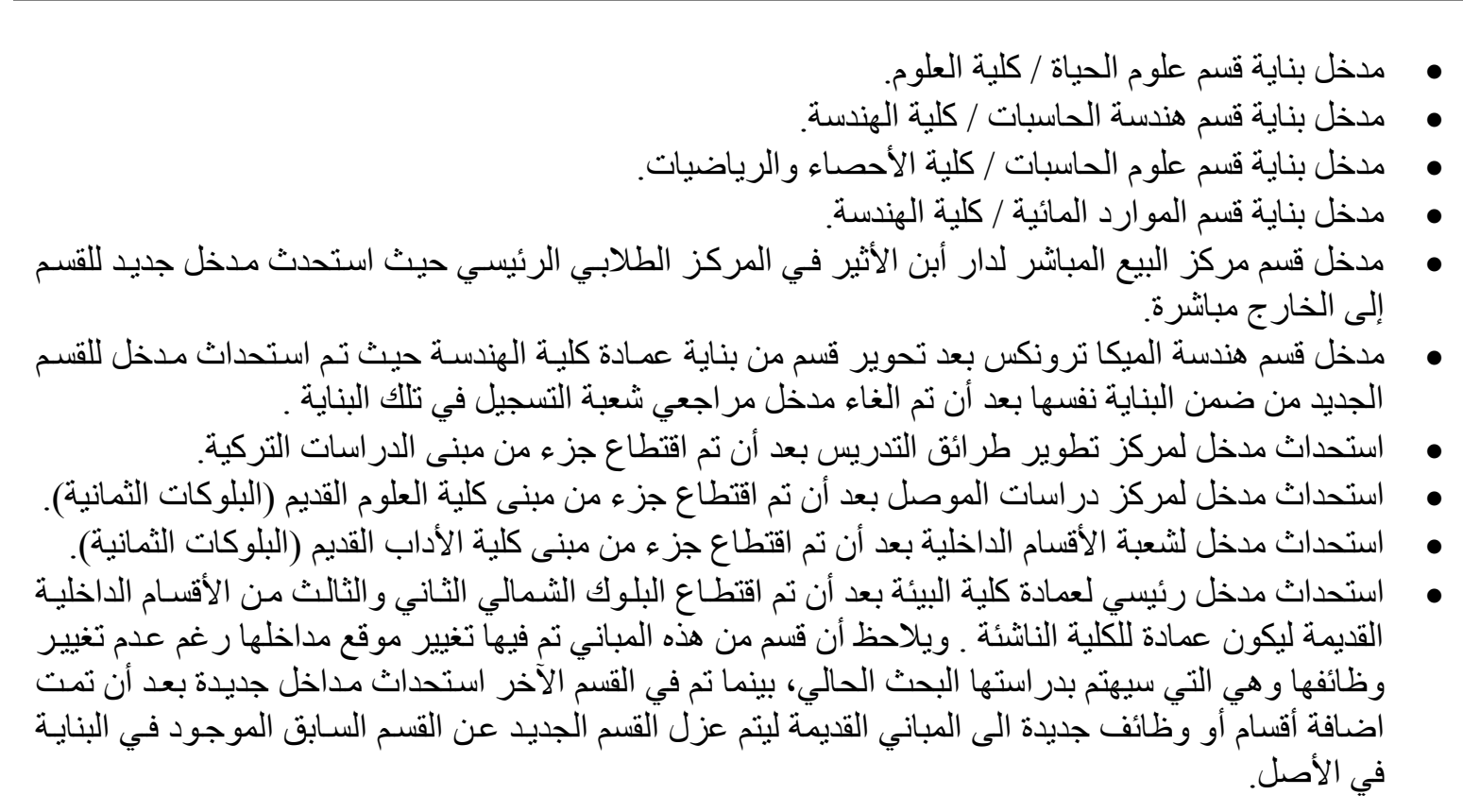

5. - 5اهرة التغير في الاراسات المعمارية السابقة

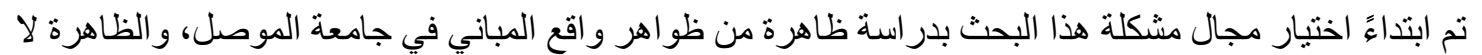

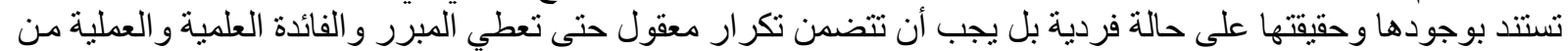
السؤ ال عن اسبابها أو طبيعتها أو ما إلى ذللك.

و الظاهرة المختارة في هذا البحث المتعلقة بتغيير مو اقع المداخل للعديد من المباني في جامعة الموصل ومنها المباني التعليمية تثير العديد من التساؤلات.

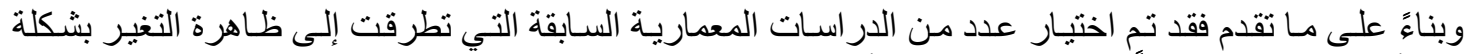

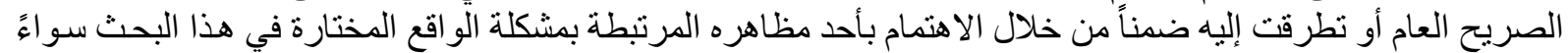

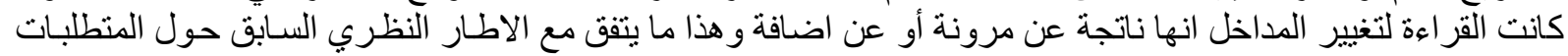

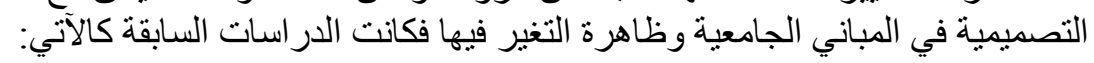

\section{"Flexibility in the Design of Building" 1-5 دراسة النجيدي 1985}

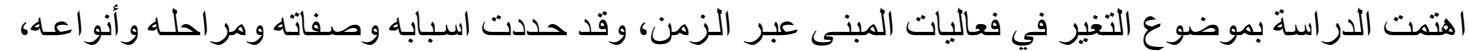

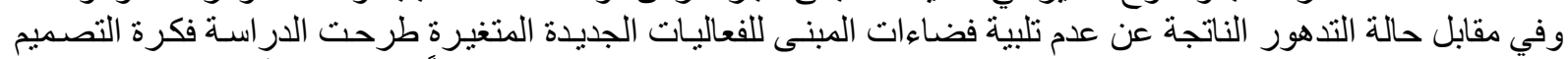

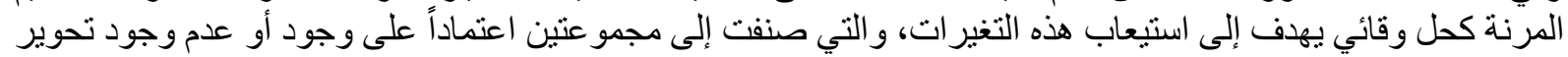
في المبنى لاستيعاب الفعاليات الجديدة المتغيرة عن ما سبق.

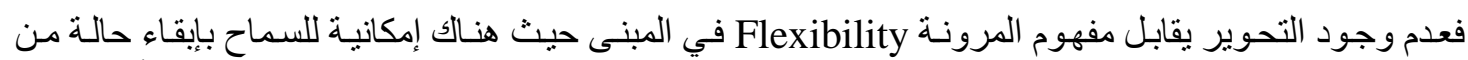

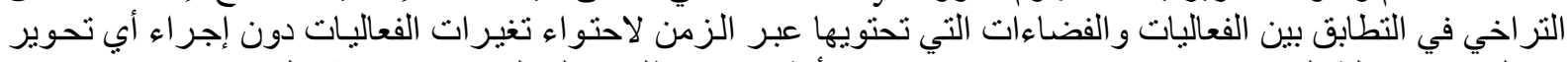

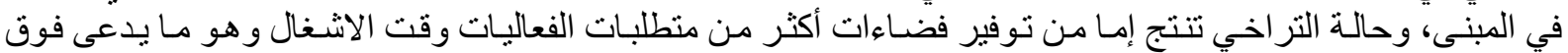

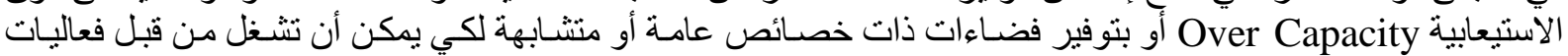
مختلفة وهو ما يدعى بالحيادية (Al-Nijaidi, p. 36) Neutrality).

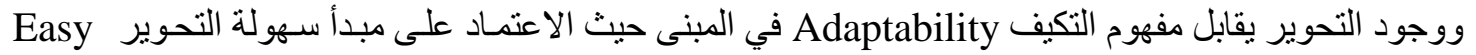

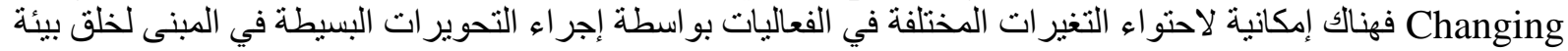
داخلية تحقق الغاية الجديدة من المبنى ولتحقيق سهولة التحوير يجب الالتز ام بالمبادئ التصميمية التالية: 
تركيز وتتميط الهيكل الانشـائي حيث يكون الهدف التقلبل مـا أمكن من نقاط الارتكـاز للهيكل الانثـائي ووضعها بالاعتماد على وحدات منكررة ذات التئ أبعاد ثابتة منمطة.

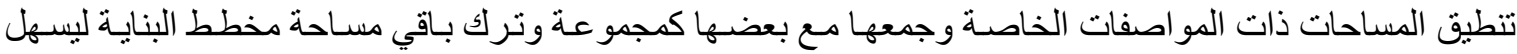
تحويره للفعالية الجديدة.

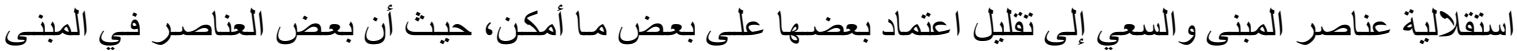

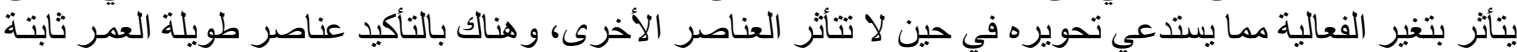

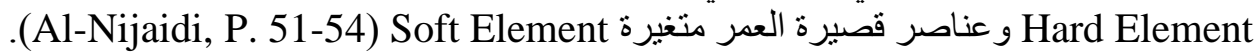

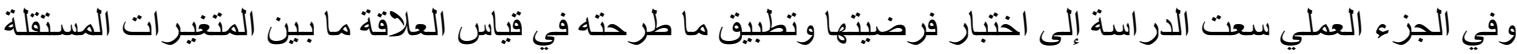
و المتمثلة بالخصائص التصميمية المرتبطة بالمرونة و المتغير المعتمد المتمثل بالمرونـة في عدد من المستشفيات في

2-5 دراسة مهدي 1989 "أثر تغير البيئة الحضرية في خصوصية العمارة"

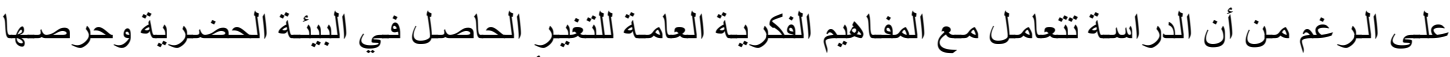

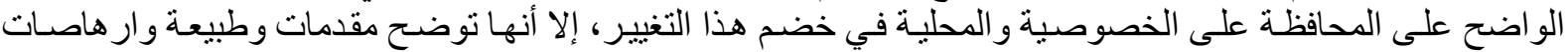
التغيرات في البيئة العمر انية، و العمارة و المباني الجامعة جزء من هذه هذه البيئة.

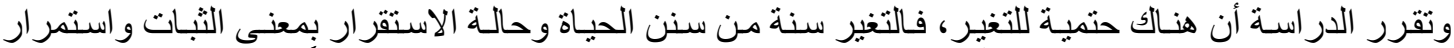
الوضع القائم حالة لم يسبق لها أن دامت طويلاً وهكذا فالعمـارة و البيئة الحضرية في في تغير ونـادر اً مـا يمكن حفظها بشكل

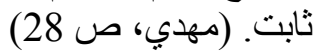

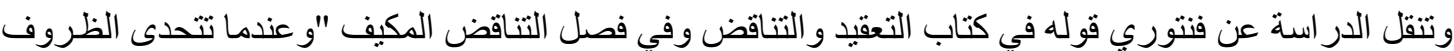

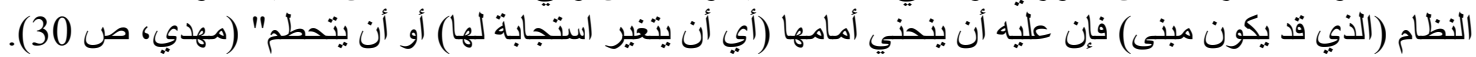

وتنتهي الدراسة إلى أن التغير في المفاهيم الفكرية والقيم الذوقية السائدة في الهتمع أثر ها في تغير البيئة و العمارة

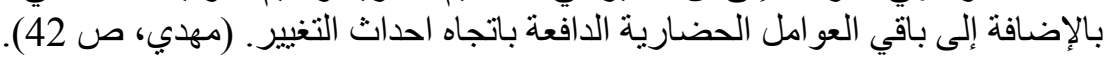

3-5 دراسة الحيالي 2001 "تغير العناصر المعمارية وأثره في عمارة الموصل"

رغم أن الدراسة عرفت العناصر المعمارية Architectural Element بأنها تلك الوحدات المميزة التي تكون

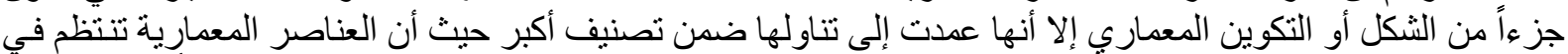

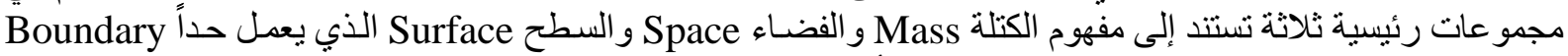

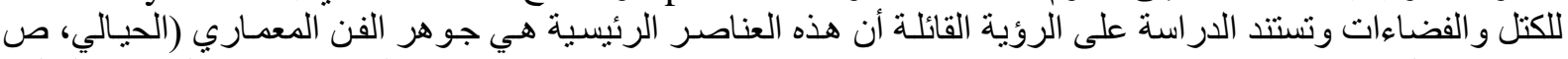

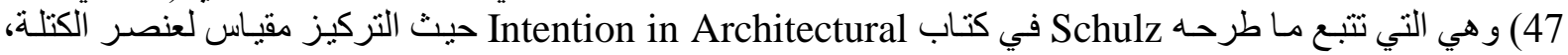
و الانغلاق مقياس لعنصر الفضاء، والاستقلالية مقياس للسطوح المحيطة. (الحيالي، ص 11).

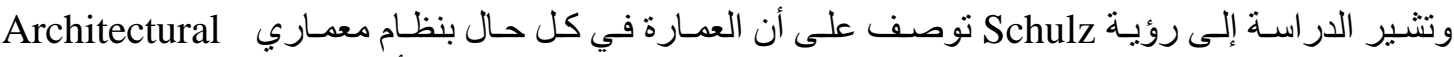

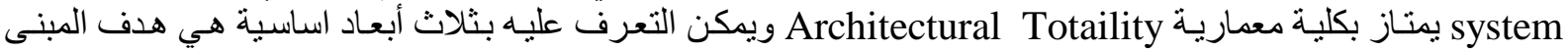
Building Task و الشكل Form و التقنية Technics (و هي تقابل ثلاثية فيتروفيوس) فالكلية هي هدف البنايـة التي تدرك

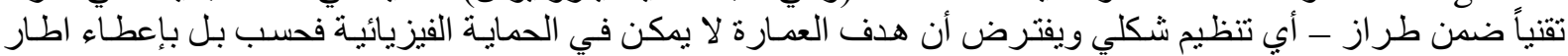

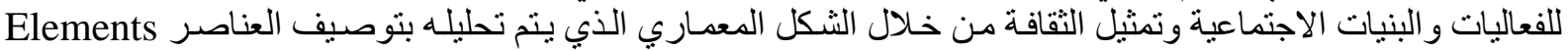

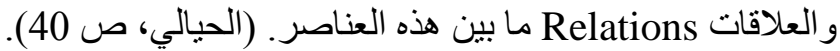

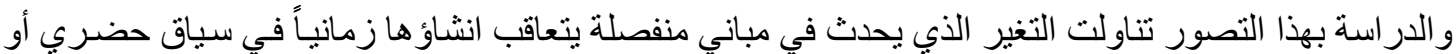

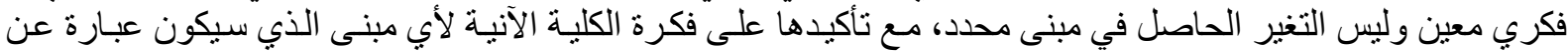

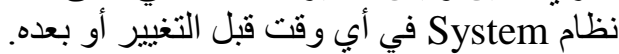


4-5 دراسة الصفو 2001 "الاضافات في العمارة"

أشـارت الدر اسة إلى أثر العو امل الطبيعية و الكو ارث و التحو لات الاقتصادية والثقافيـة و الاجتماعية، بـل في أحيان

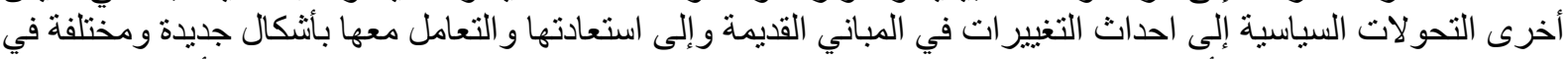

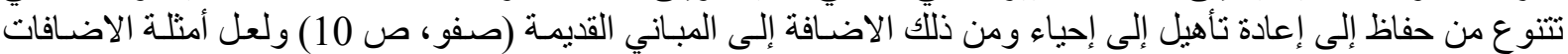

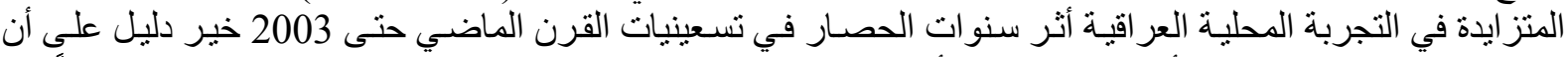

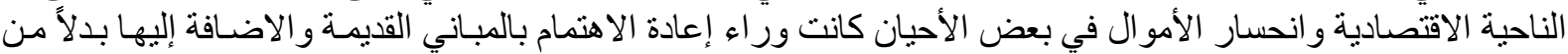

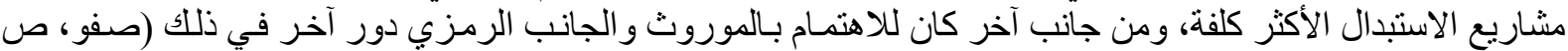

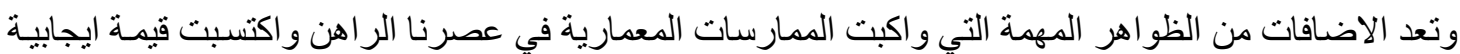

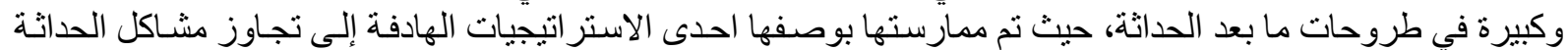

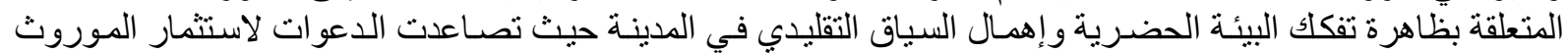

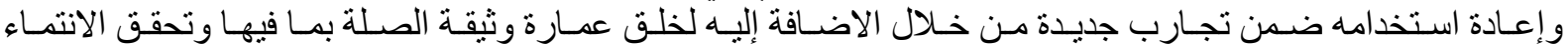

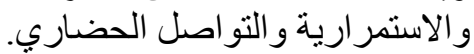

وقد اكتسبت ظـاهرة الاضـافة قيمـة ايجابيـة في توجهين أساسيين مـن توجهات مـا بعد الحداثنة، ارتبط احدهما بالتصميم الحضري و السياقية Urbanism and Contextualism ، بينما ارتبط الثاني بإعادة التأهيل Rehabilitation / الحفاظ Restriction / الاحياء Preservation . (صفو، ص 1-5 (5)

وتثبير الدراسة إلى أن المبنى الذي بتعرض للإضافة لم يعد هو ذاته قبل الاضافة، بل يصبح بنية جديدة مختلفة في

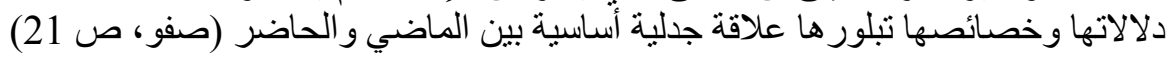

و واستر اتيجية اضافة كيان جديد إلى آخر موجود مسبقاً بصيغة معينة تنت في اطـار نوجها معين إزاء مسألة الثكل

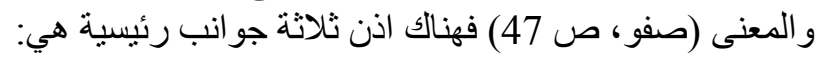

$$
\text { - - }
$$

5-5 دراسة النعمان 2003 "الخصائص التصميمية المؤثرة في مرونة الحركة في الفضاءات الداخلية للأبنية الجامعية ـ جامعة الموصل نموذجاًا"

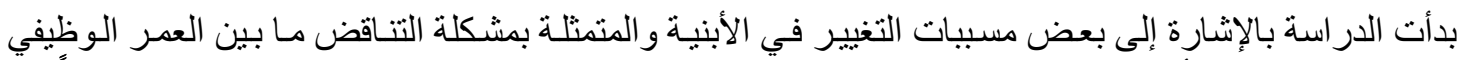

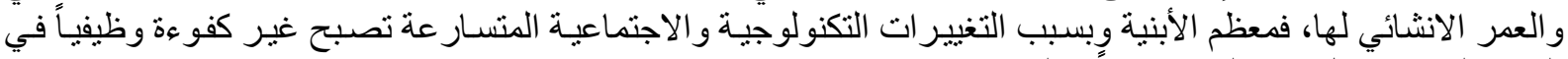

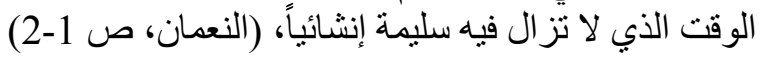
ومسببات ظاهرة التغير التي قدمنها الدر اسة تتعلق بـ:

$$
\begin{aligned}
& \text { - - مالتغير في الجوانب التكنولوجية و الاجتماعية. } \\
& \text { - - - التغير في المعايير و المو اصفات. } \\
& \text { - - مالتغير في الاعتبار ات الوظيفية. }
\end{aligned}
$$

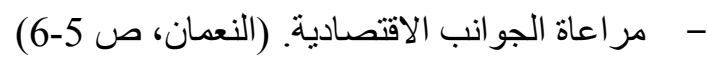

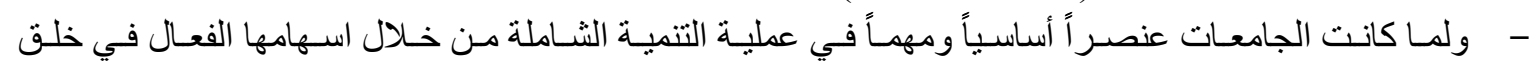
التكنولوجيا وتوسيع القاعدة المعرفية.

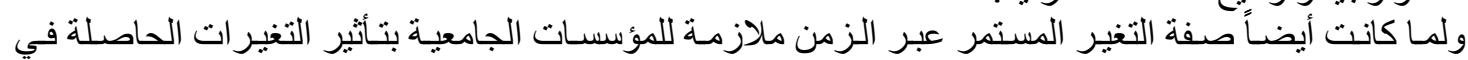

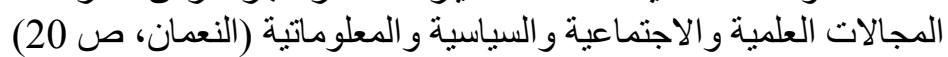


ومن جهة أخرى كانت مباني جامعة الموصل خير مثال للتغيير في المباني الجامعية و الذي توصلت إليـه الدراسـة

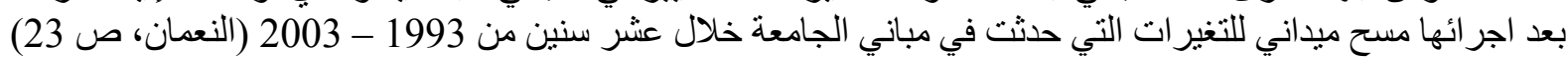
قدمت الدر اسة المبررات ووضدت الأهمية لدر اسة الميدان الجامعي الذي يعد و اسعاً وخصباً للعديد من الدر اسـات

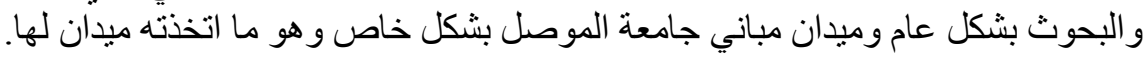

ومن ثم اتجهت الدر اسة نحو مفهوم المرونة في الأبنية الجامعية الذي يعد الإجابة الأولى و الحتمية لمشكلة التغيير

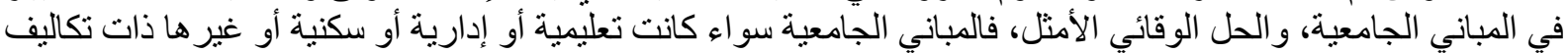

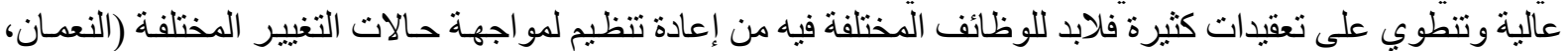

و أشنارت الدر اسة أيضاً إلى تصنيف Lang السابق ذكره التي يسبيها البشر في المباني إلى نوعين:

- - - التغير التكيفي الذي يحصل بطبيعة متنامية وبصورة غبر واعية وغالباً ما يكون في الفعالية التي تشغل الفضاء.

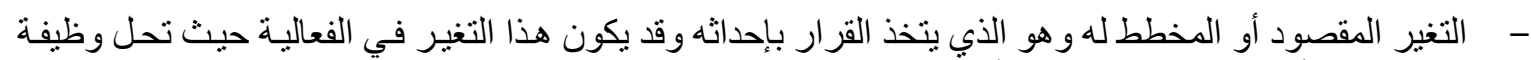

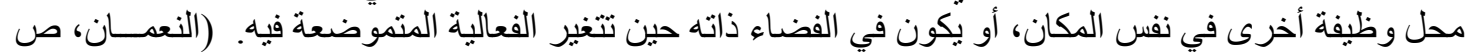

و هدفت الدر اسة إلى تحديد وبيان طبيعة العلاقة بين خصائص تصميمية خاصة بنمط الحركة للفضاءات الداخلية للأبنية

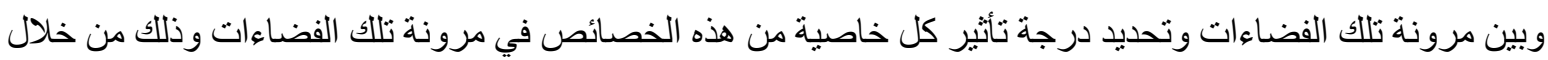

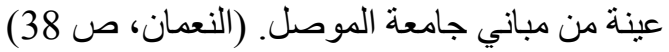
ونم في الدر اسة العملية توظيف منهجية تركيب الفضاء كوسيلة للقياس.

6 ـ تحديد مشكلة البحث وهدفه وفرضيته الرئيسة

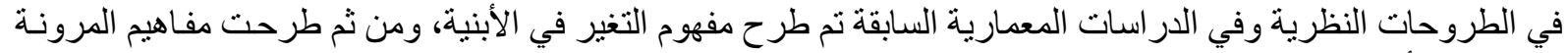

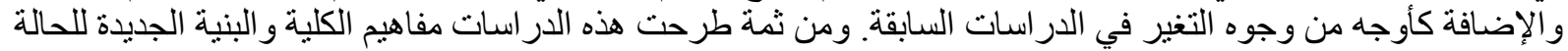

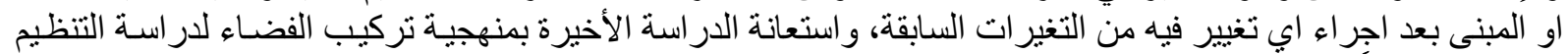

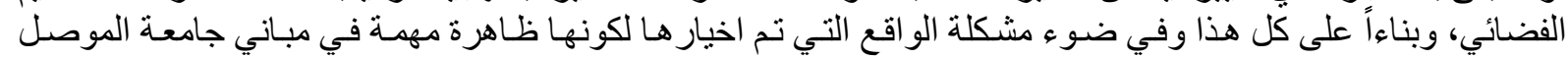

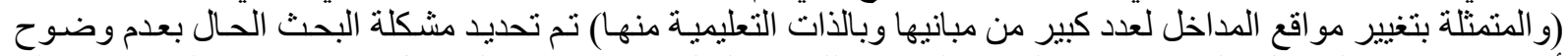

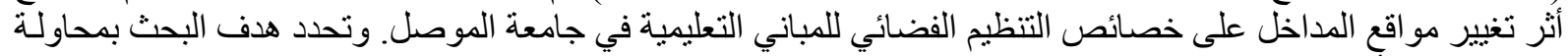

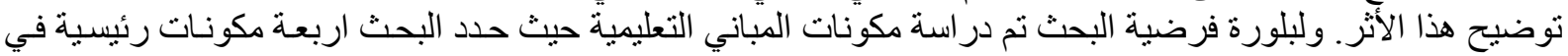

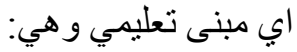

- الجزء التعليمي: الذي يضم القاعات الدر اسية و المختبر ات و المر اسم و المكتبة.

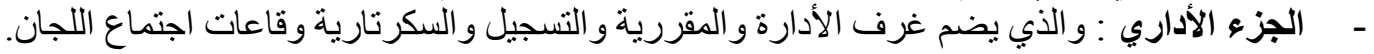
- جزء التدريسين : ويضم غرف الأفي التدريسين.

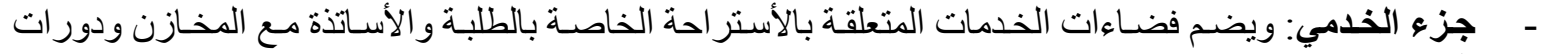
المياه.

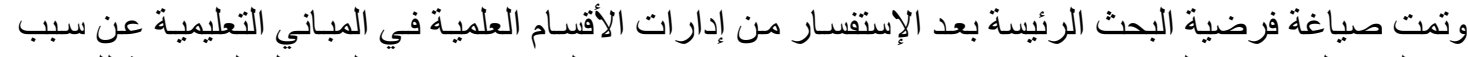

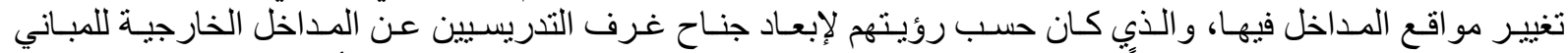

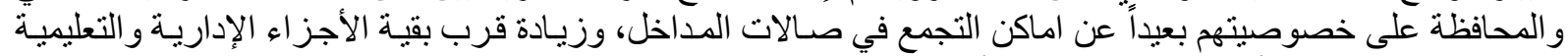

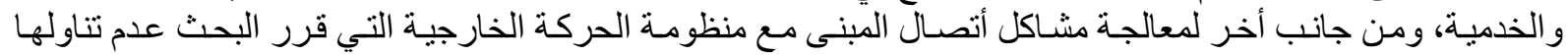
وتركها لمشاريع بحنية لاحقة. 
فكانت فرضية البحث الرئيسة هي أن مداخل الأبنيـة التعليمية التي جرى تغير مو اقعها كانت بهدف تأمين عزل

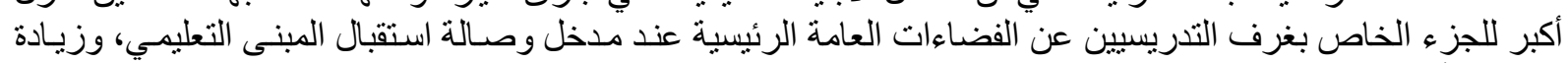
ارتباط الأجز اء الإدارية و التعليمية والخدمية بنية معها.

\section{7. الفضاء والتنظيم الفضائي في المباني}

الفضاء في اي مبنى حسب ching هو المادة الاولية prime material تماما كالحجر أو الخشب رغم أنس غير

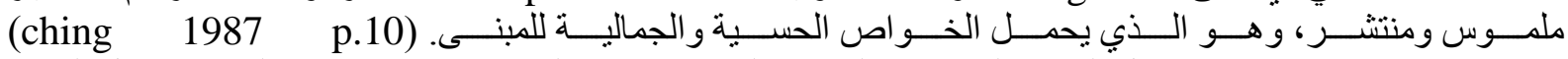

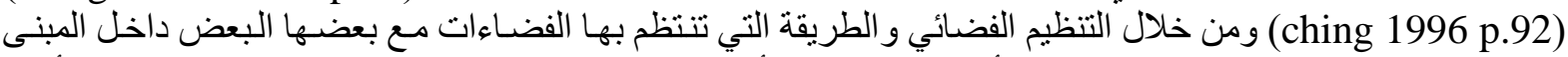

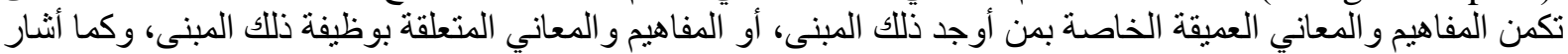

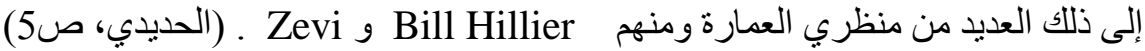

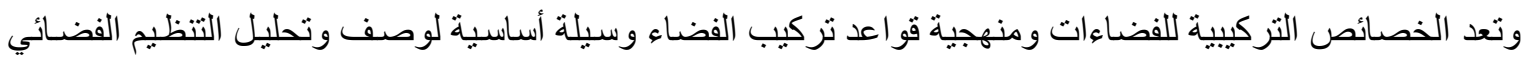
وبموجب طروحات هذه المنهجية فإن التنظيم الفضـائي يمكن تحليله بوصفه منظومـة من العلاقات التركيبية ـ يمكن تحليل هذه العلاقات التركيبية وفق خاصيتين أساسيتين هما:

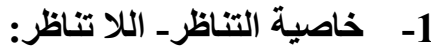

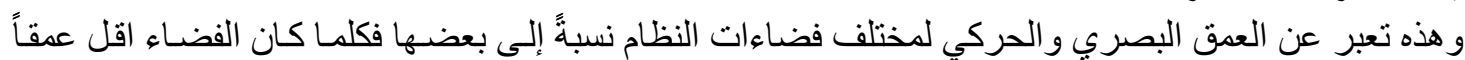

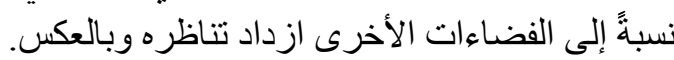

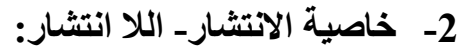

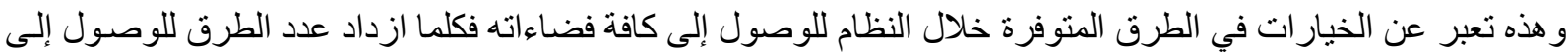
فضاء معين ازداد انتشاره في النظام وبالعكس ـ ولغرض قياس هاتين فئن الخاصيتين يتم اعتماد المؤشرين التاليين:

خاصية معدل العمق النسبي Mepth Dean

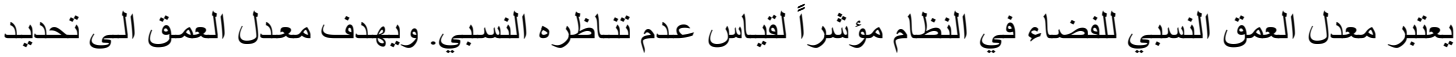

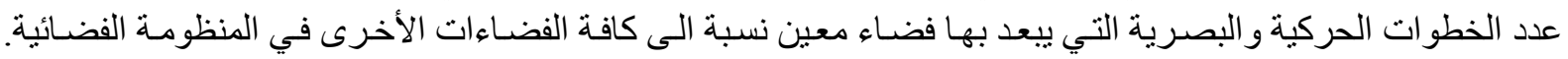
ويتحقق أقل عمق حينما تكون جميع الفضاءات مرتبطة بتسلسل خطي نسبة الى الفضاء الأصلي، ويتحقق أكبر عمق عن عندما

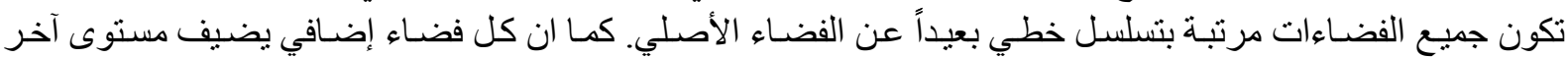
للعمق.

$$
\mathrm{MD}=\frac{\sum \mathrm{DK}}{\mathrm{K}-1}
$$

ويتم قياس معدل العمق باستخدام المعادلة التالية : (Hillier, 1996, P. 108)

$$
\text { حيث MD : عمدل العمق النسبي : عمدي }
$$

عمق الفضاءات الأخرى نسبة الى الفضاء الأساسي ويحسب من عدد الخطوات البصرية التي يبعد بها عن الفضـاء : DK

$$
\text { ع : عدد الفضاءات المحورية : K }
$$

وتثير انخفاض قيمة معدل العمق الى قوة علاقة الفضـاء مـع كافة فضـاءات المنظومـة، بينمـا ارتفاع قيمـة معدل

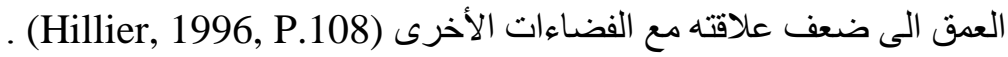

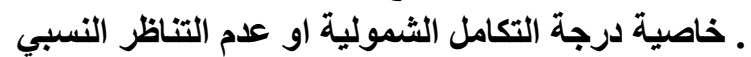

تعبر خاصية التكامل عن العهق النسبي للفضـاء نسبة الى بقيـة الفضـاءات للمخطط المحوري، ويعتبر مقيساس التكامل أهم المقاييس التركيبية الثمولية (Hillier, 1993, P.35) .

Relative Asymmetry $\quad \mathrm{RA}=\frac{2(\mathrm{MD}-1)}{\mathrm{K}-1}$ 


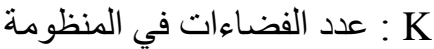

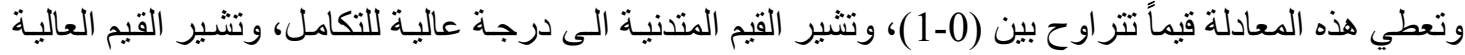

الى درجة عالية للانعز ال عن المنظومة الثمولية (Hillier, 1984, P.108) .

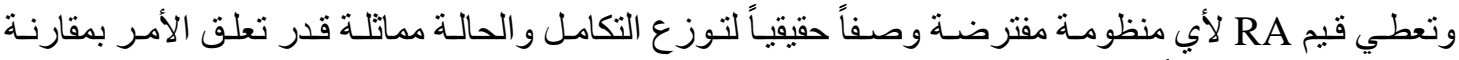

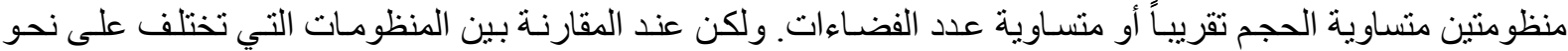

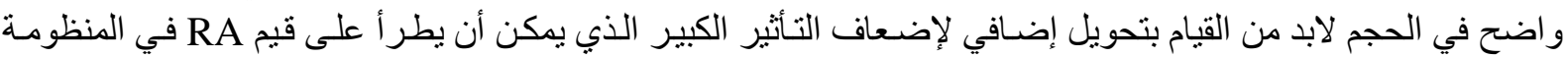

الحقيقية Real system.

وبالنتيجة فان ما نفعله هو مقارنة RA التي لدينا مع قيمة RA للجذر (وهو الفضاء في أسفل مخطط العمق) للنمط

الجو هري (diamond - shapped) او مخطط العمق الهرمي نصف الجوهري (Pyramid - Shapped) حيث يمثل

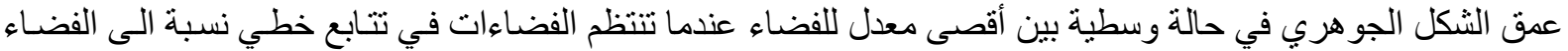

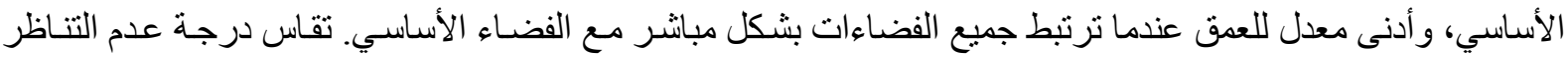
$\mathrm{RRA}=\frac{\mathrm{RA}}{\mathrm{DK}}$ النسبي المعدل (Hillier, 1984, P. 113) RRA (Relative Asymmetry)

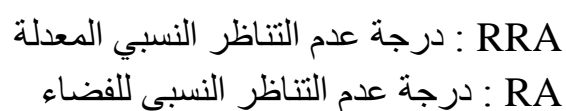
DK درجة عدم التناظر النسبي للفضاء من مخطط العمق الجو هري للنشكل.

8.

تم اختيار اربعة مباني تعليمية من مباني جامعة الموصل التي تغيرت مداخلها لتكون نمـاذج منتخبـة لعينـة البحث

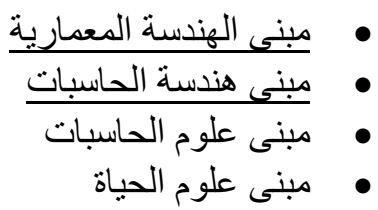

وتم اعداد المخططات الخاصة بكل مبنى قبل وبعد تغير المداخل، ومن ثم تم تحليل هذه المخططات وفق المكونات

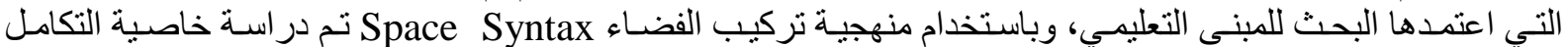
وخاصية العمق لمكونات هذه المباني قبل وبعد تغير المداخل، والأشكال (4,3,2,1) توضـح مخططات الأبنية و المخطط

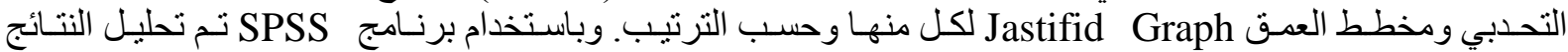

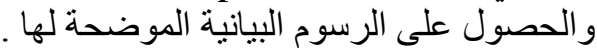

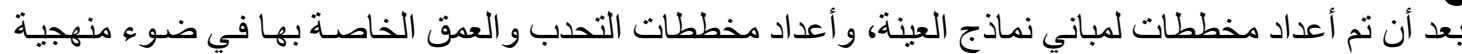
9 9 النتائج والاستنتاجات:

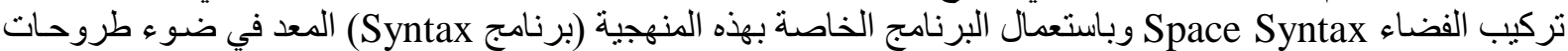

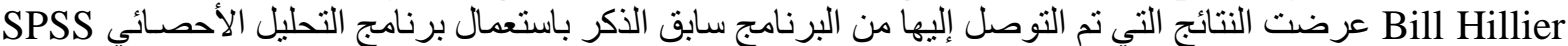

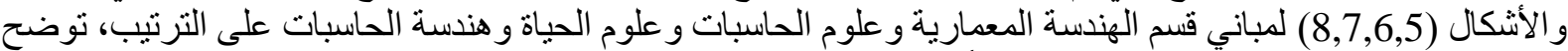
نتائج قيم التكامل والعمق للمكونات الأربعة لكلاً منها قبل وبعد تغيير المداخل. 
العزاوي: أثر تغير موقع المداخل على خصائص التنظيم الفضائي للمباني التعليمية في جامعة الموصل

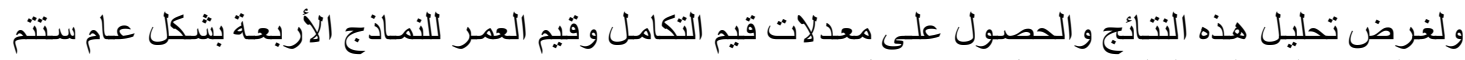

صياغة نتائج البحث بالجدولين التاليين (جدول -1 النيأج)(جدول-2).

\begin{tabular}{|c|c|c|c|c|c|c|c|c|c|c|}
\hline العينة & \multicolumn{2}{|c|}{ مبنى الهندسة } & \multicolumn{2}{|c|}{ مبنى هندسة } & \multicolumn{2}{|c|}{ مبنى علوم } & \multicolumn{2}{|c|}{ مبنى علوم الحياة } & \multirow{2}{*}{ تلغيير اللمباني بعدل } & \multirow{2}{*}{ اللألتبانيل } \\
\hline & بعد & قبل & بعد & قبل & بعد & قبل & بعد & قبل & & \\
\hline التعليمي & 0.33 & 1.37 & 1.88 & 1.23 & 1.06 & 1.14 & 1.15 & 0.96 & 1.105 & 1.175 \\
\hline الأدارة & 0.69 & 1.613 & 1.59 & 1.29 & 1.07 & 1.20 & 1.12 & 1.03 & 1.117 & 1.283 \\
\hline تدريسين & 0.3 & 1.352 & 2.31 & 1.20 & 1.11 & 0.90 & 1.04 & 0.91 & 1.19 & 1.09 \\
\hline الخدمي & 0.42 & 1.624 & 1.58 & 1.20 & 1.14 & 1.27 & 1.30 & 1.01 & 1.11 & 1.276 \\
\hline
\end{tabular}

(جدول -1) يمثل قيمة التكامل لمكونات المباني التعليمية قبل وبعد تغيير موقع المداخل

\begin{tabular}{|c|c|c|c|c|c|c|c|c|c|c|}
\hline العينة & \multicolumn{2}{|c|}{ مبنى المعندسة } & \multicolumn{2}{|c|}{ مبنى هندسة } & \multicolumn{2}{|c|}{ مبنى علوم } & \multicolumn{2}{|c|}{ مبنى علوم الحياة } & \multirow{2}{*}{ تغعيير اللمباني العمد } & \multirow{2}{*}{ للمباني الأربعة العمق } \\
\hline & بعد & قبل & بعد & قبل & بعد & قبل & بعد & قبل & & \\
\hline التعليمي & 2.28 & 5.53 & 6.03 & 4.95 & 4.67 & 4.90 & 4.76 & 4.02 & 4.435 & 4.85 \\
\hline الأدارة & 3.65 & 6.33 & 5.88 & 5.12 & 4.70 & 5.13 & 4.67 & 4.25 & 4.735 & 5.207 \\
\hline تدريسين & 2.99 & 5.46 & 8.08 & 4.86 & 4.83 & 4.10 & 4.40 & 3.85 & 5.075 & 4.542 \\
\hline الخدمي & 2.34 & 6.36 & 5.86 & 4.83 & 4.93 & 5.35 & 5.24 & 4.18 & 4.592 & 5.18 \\
\hline
\end{tabular}

(جدول -2) يمثل قيمة العمق لمكونات المباني التعليمية قبل وبعد تغيير موقع المداخل

و النظرة العامة على نتائج التكامل قبل وبعد تغير مداخل نماذج العينة تظهر ما يلي:

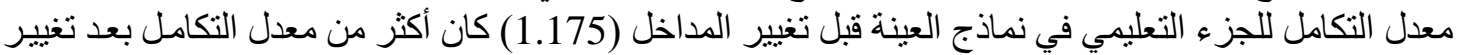

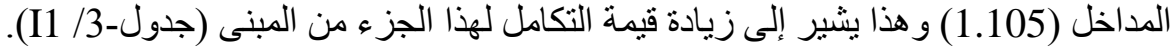

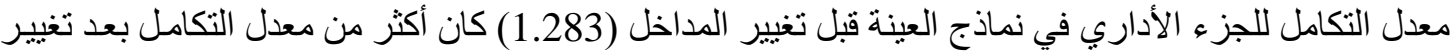

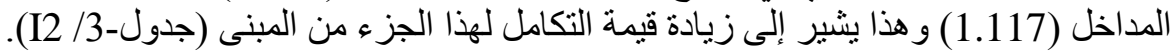

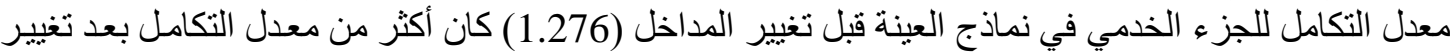

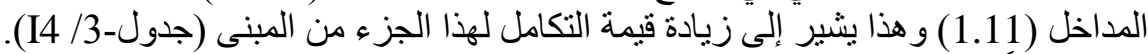

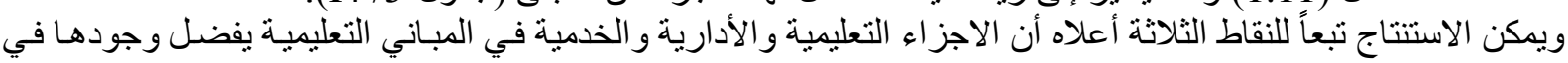

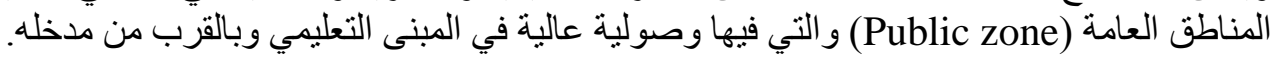

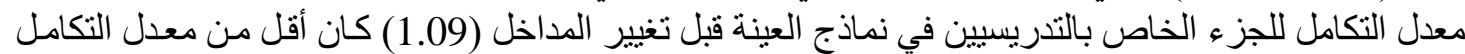

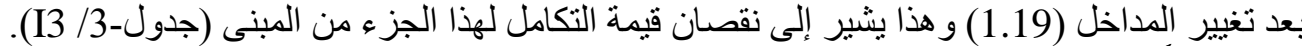

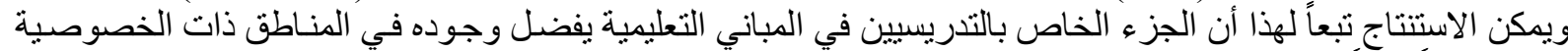

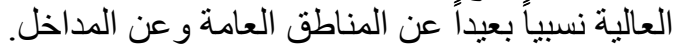

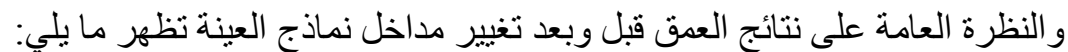

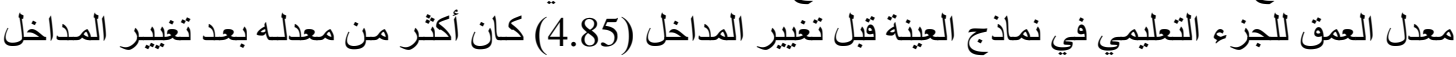

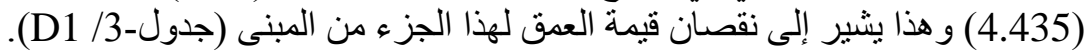

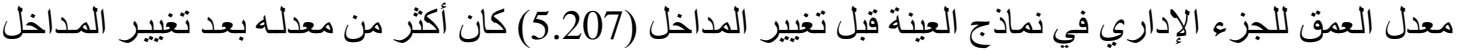

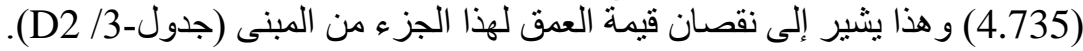


هعدل العمق للجزء الخدمي في نماذج العينة قبل تغيير المداخل (5.18) كان أكثر من معدله بعد تغيير المداخل

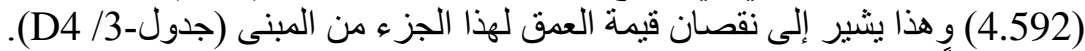

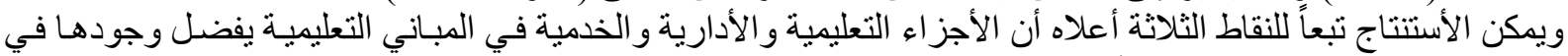

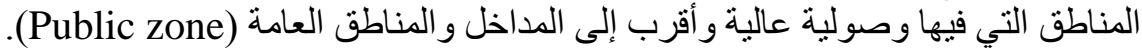

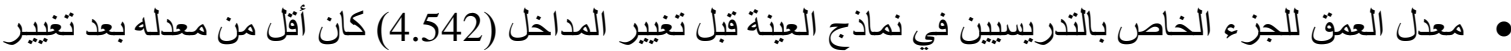

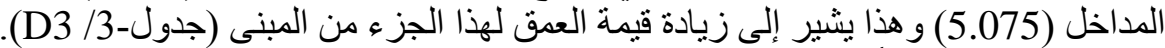

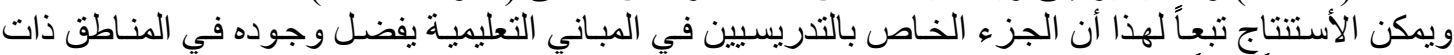
الخصوصية العالية نسبياً بعيداً عن المناطق العزان العزة القريبة من المداخل في المباني التعليمية.

\begin{tabular}{|c|c|c|c|c|}
\hline الجزء الخدمي & غرف التدريسيين & الجزء الأداري & الجزء التعليمي & المكونات \\
\hline 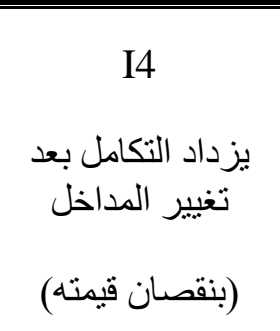 & 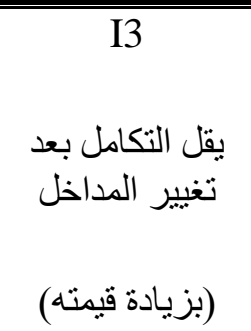 & 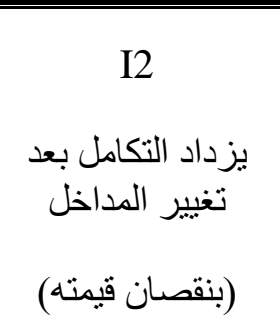 & 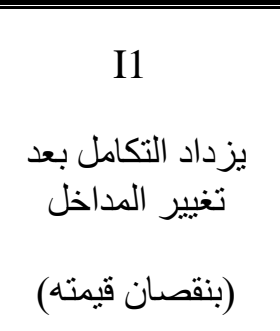 & $\begin{array}{c}\text { التكامل } \\
\text { Integration }\end{array}$ \\
\hline $\begin{array}{c}\text { D4 } \\
\text { يقل العمق بعد تغيير } \\
\text { بلمداخل }\end{array}$ & $\begin{array}{c}\text { D3 } \\
\text { تغيير المداد العمق بعد }\end{array}$ & $\begin{array}{c}\text { D2 } \\
\text { يقل العمق بعد تغيير } \\
\text { بلمداخل }\end{array}$ & $\begin{array}{c}\text { D1 } \\
\text { يقل العمق بعد تغيير } \\
\text { بلمداخل }\end{array}$ & العمق \\
\hline
\end{tabular}

$$
\text { (جدول -3) نتائج البحث }
$$

كما ويمكن تفسير نتائج التحليل للتكامل و العمق لكل نموذج من نمـاذج العينـة على حدة وبـالرجوع الى مخططسات

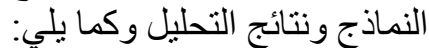

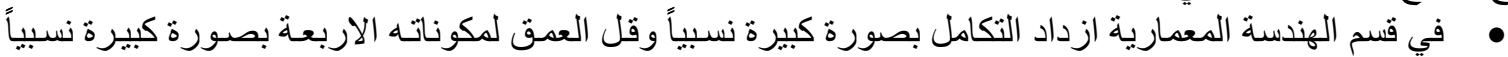

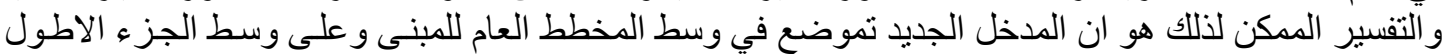

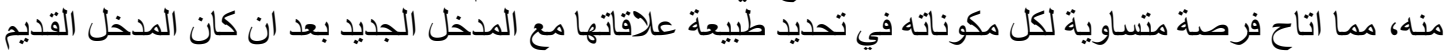

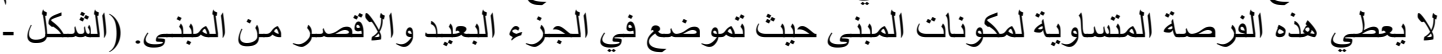

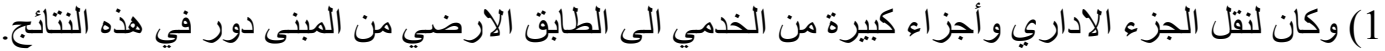

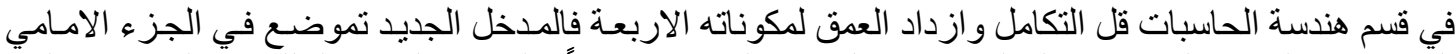

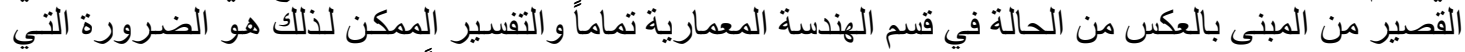

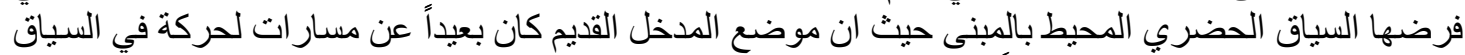
الحضري في الجامعة ومنعزل نسبياً.

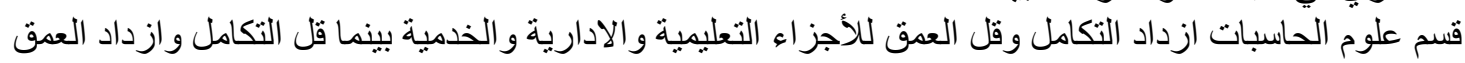

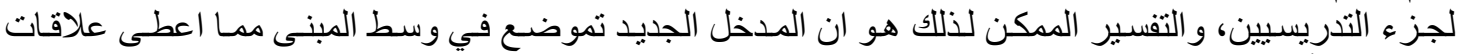

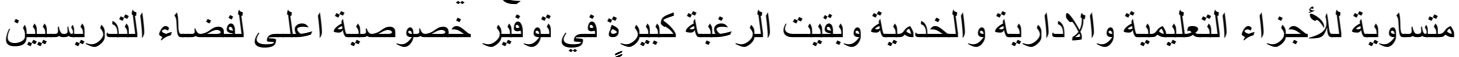

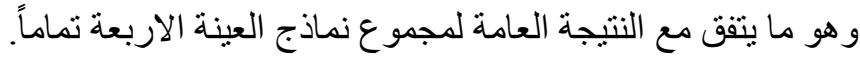




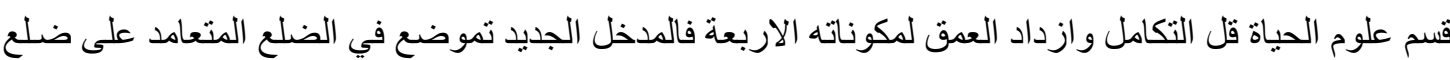

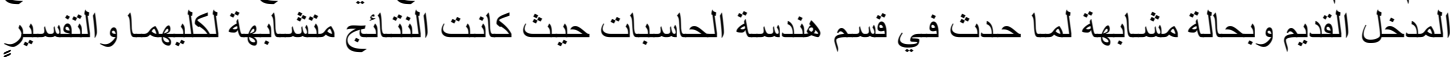

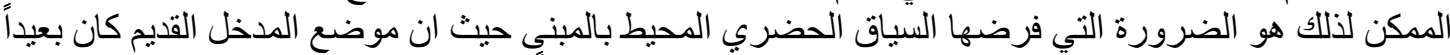

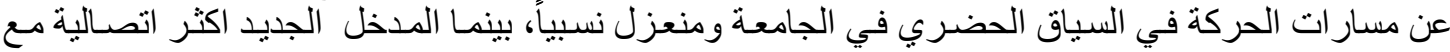
مسار ات الحركة في السبّاق الحضري في الجامعة.

التوصيات: - ات

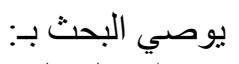

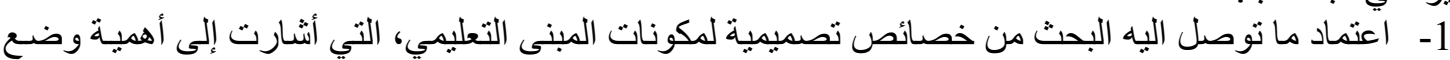

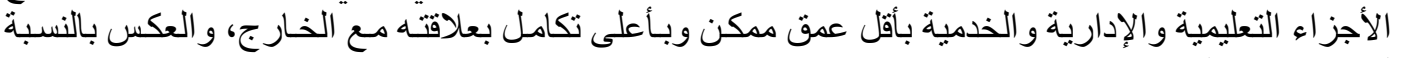
لجناح غرف التدريسيين.

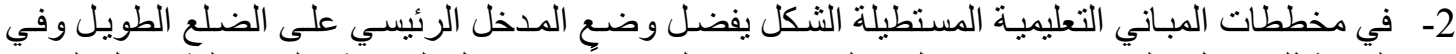

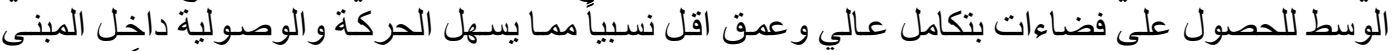
حيث اشرت المداخل الو اقعة على الضلع القصير أي على المحور الطولي للمخطط المستطيل المبل تبايناً في تكامل

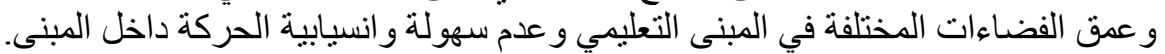

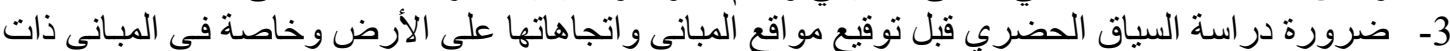

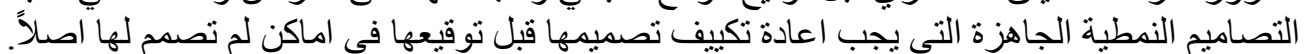

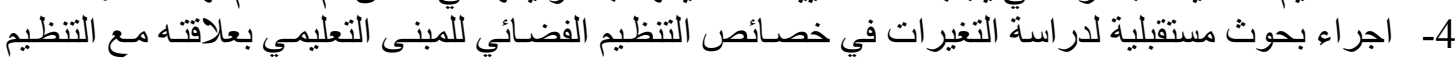
الفضائي للسباق الحضري في المباني الجامعية التي تم تغيير مداخلها. 
No. 3

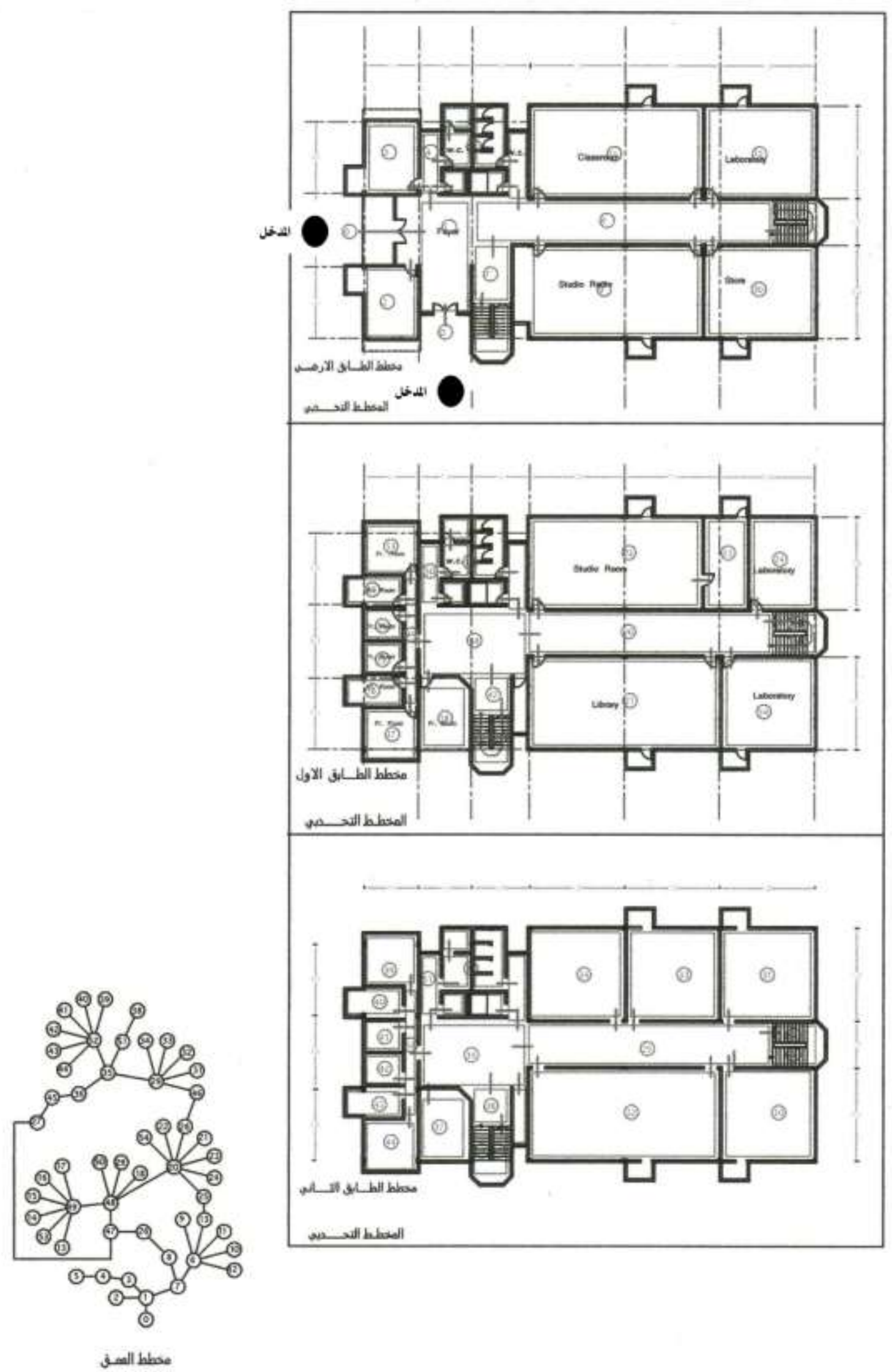

الثكل (1-أ) مخططات قسم الهندسة المعمارية مع المخطط التحدبي ومخطط العمق قبل تغيير المدخل 


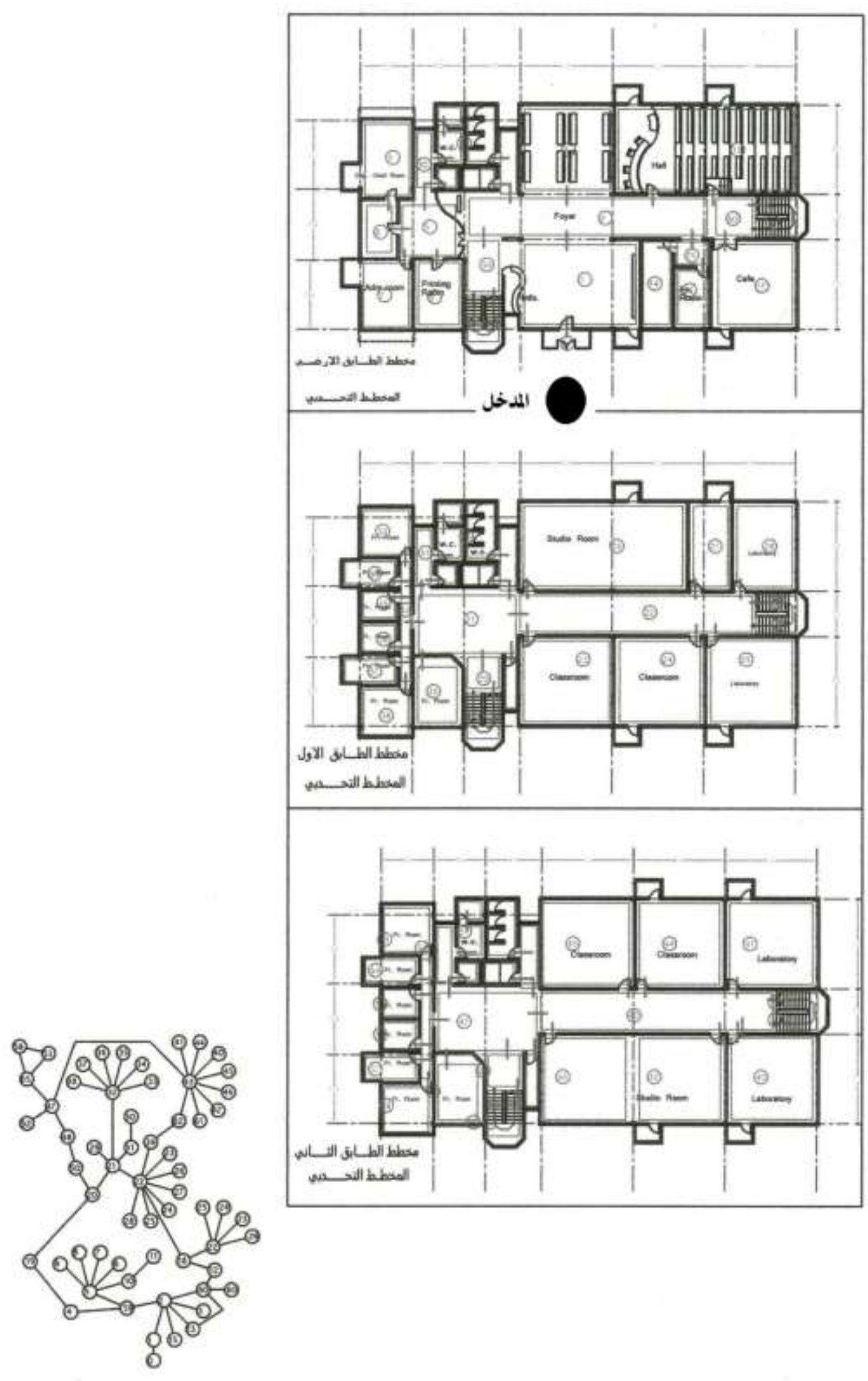

Juall bhose

الثكل (1- ب) مخططات قسم الهندة المعمارية مع المخطط التحدبي ومخطط العمق بعد تغيير المدخل 
No. 3
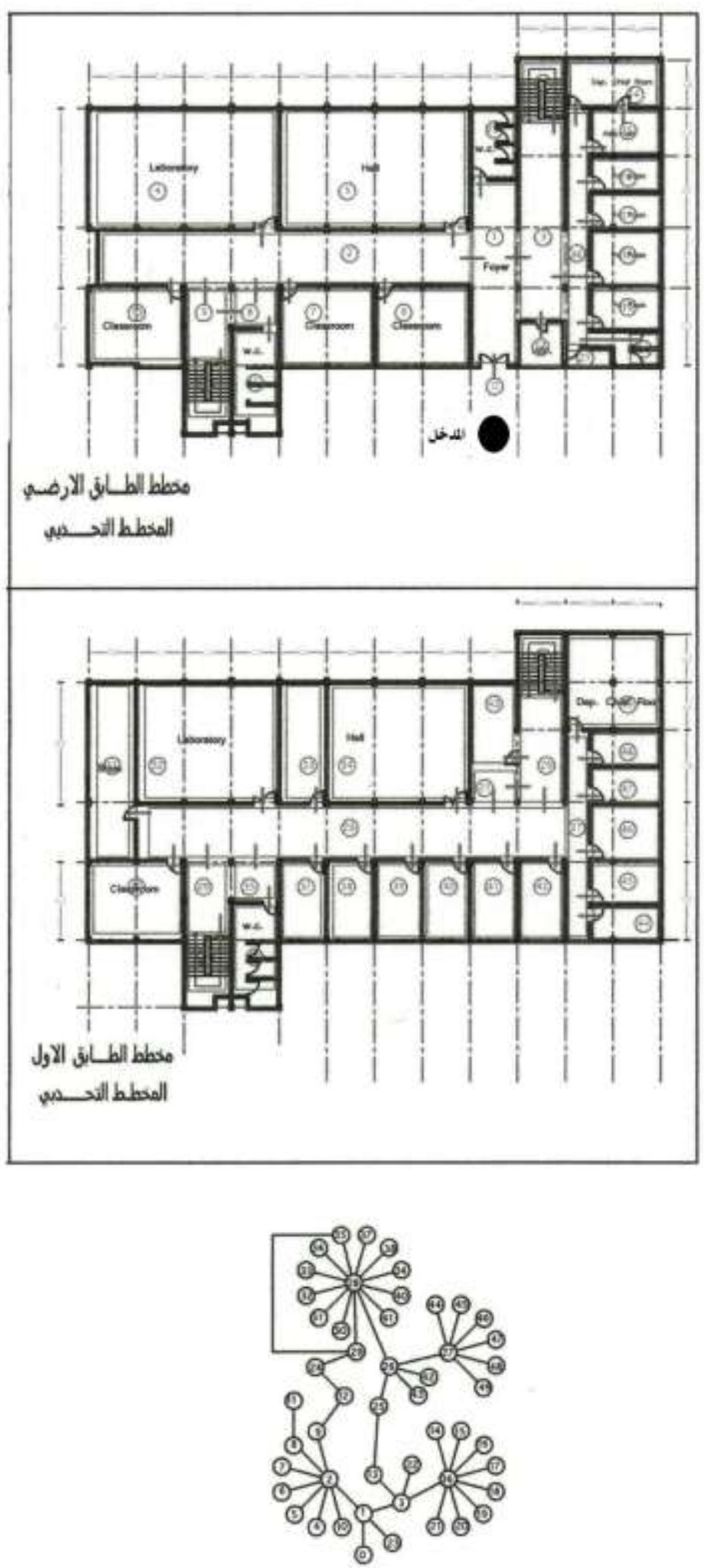

كceall

الثكل (2- أ) مخططات قسم هندسة الحاسبات مع المخطط التحدبي ومخطط العمق قبل تغيير المدخل 
العزاوي: أثر تغير موقع المداخل على خصائص التنظيم الفضائي للمباني التعليمية في جامعة الموصل
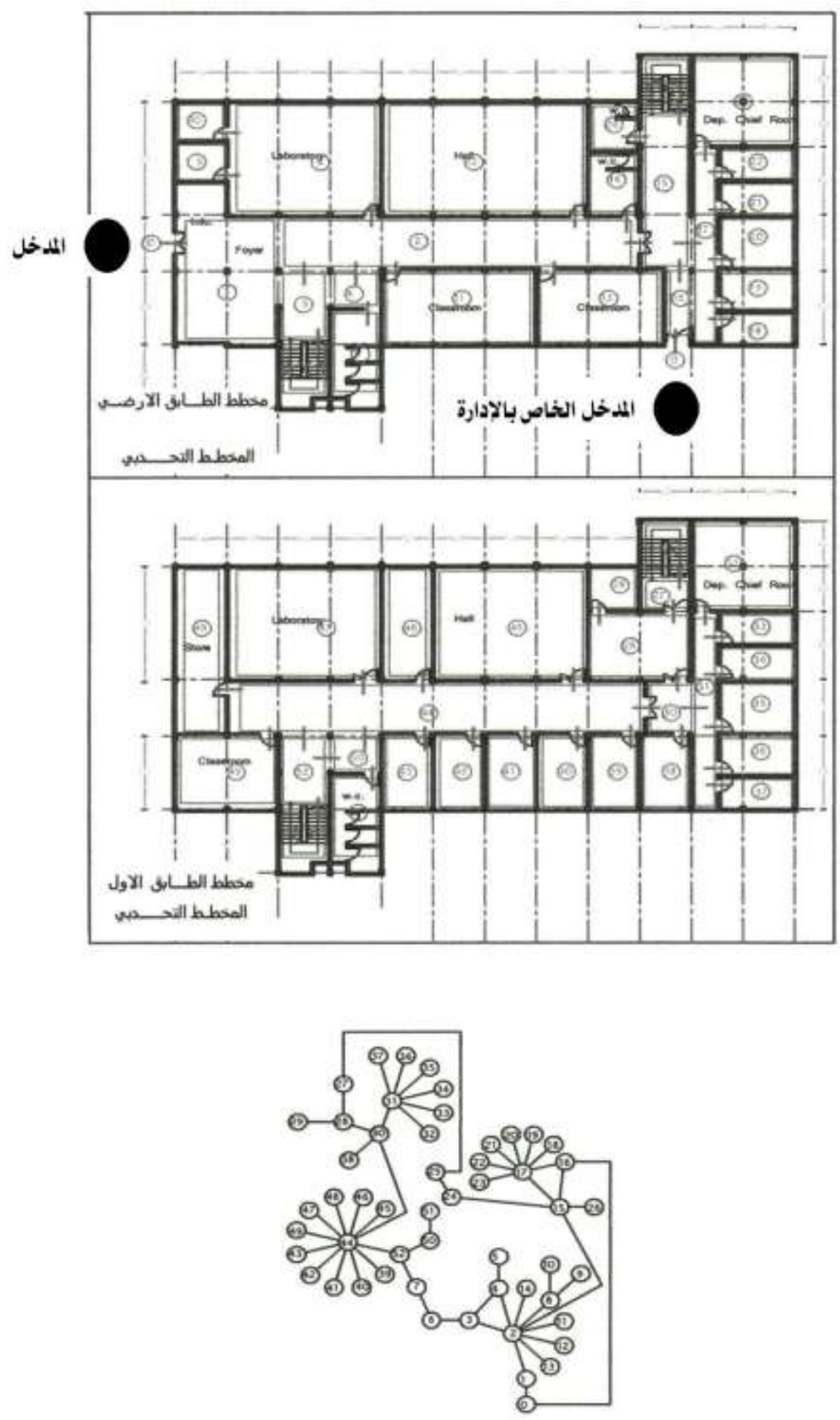

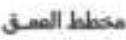

الثكل (2- ب) مخططات قسم هندسة الحاسبات مع المخطط التحدبي ومخطط العمق بعد تغيير الدذخل 
No. 3

April 2014

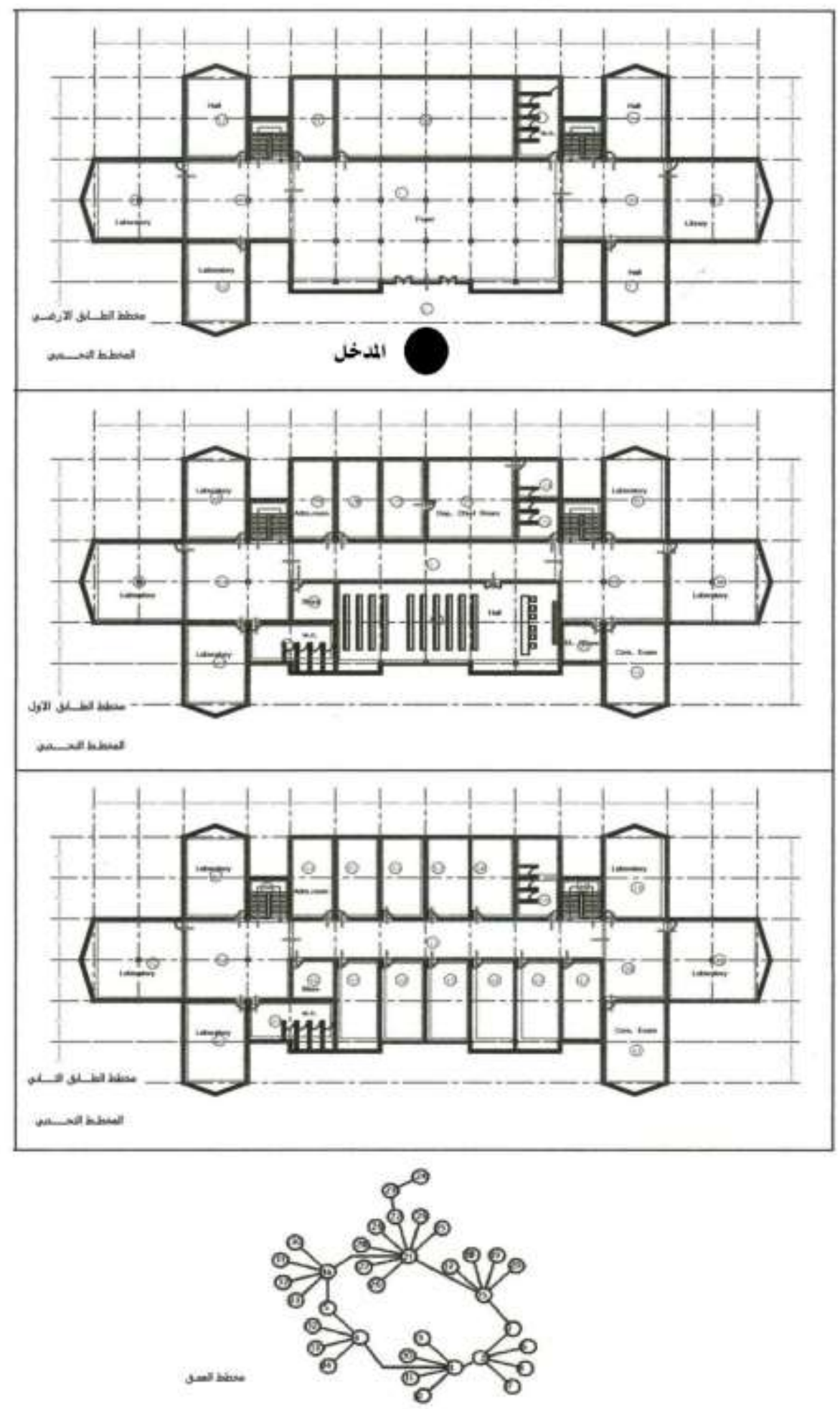

الثكل (3- أ) مخططات قسم علوم الحاسبات مع المخطط التحدبي ومخطط العمق قبل تغيير المدخل 
العزاوي: أثر تغير موقع الدداخل على خصائص التظظيم الفضائي للمباني التعليمية في جامعة الموصل

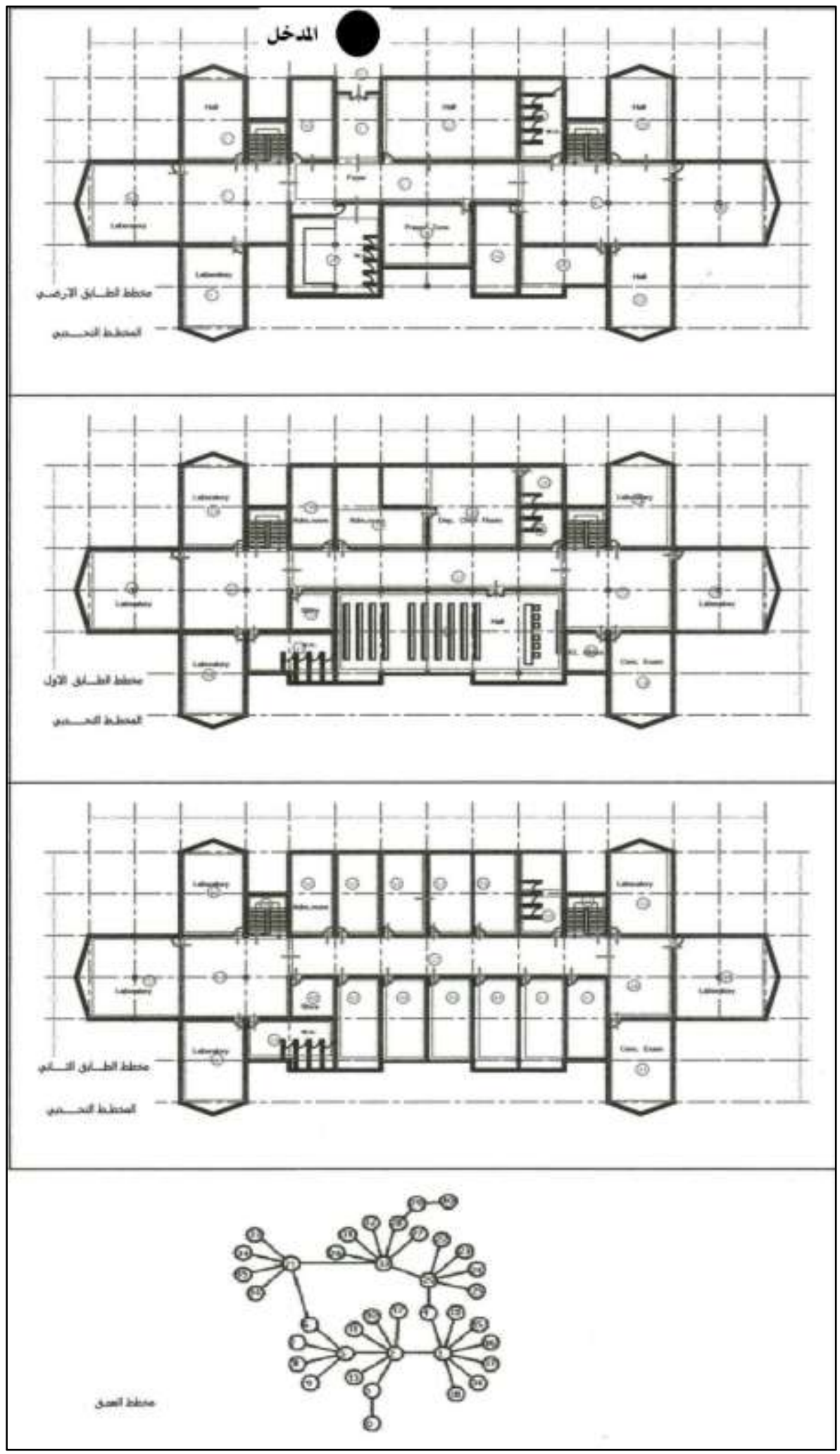

الشكل (3- ب) مخططات قسم علوم الحاسبات مع المخطط التحدبي ومخطط العمق بعد تغيير الدخل 
No. 3
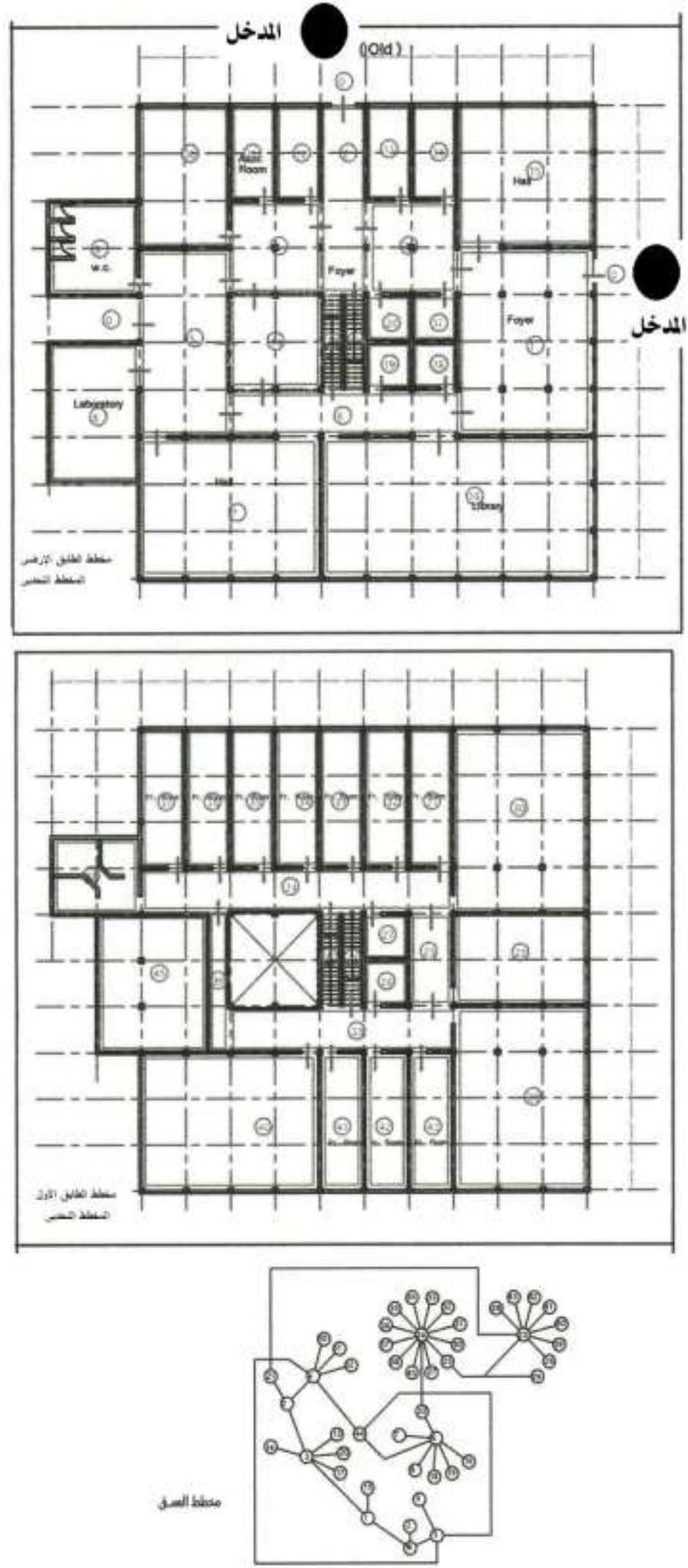

الثكل (4- أ) مخططات قسم علوم الحياة مع المخطط التحدبي ومخطط العمق قبل تغيير الدذخل 


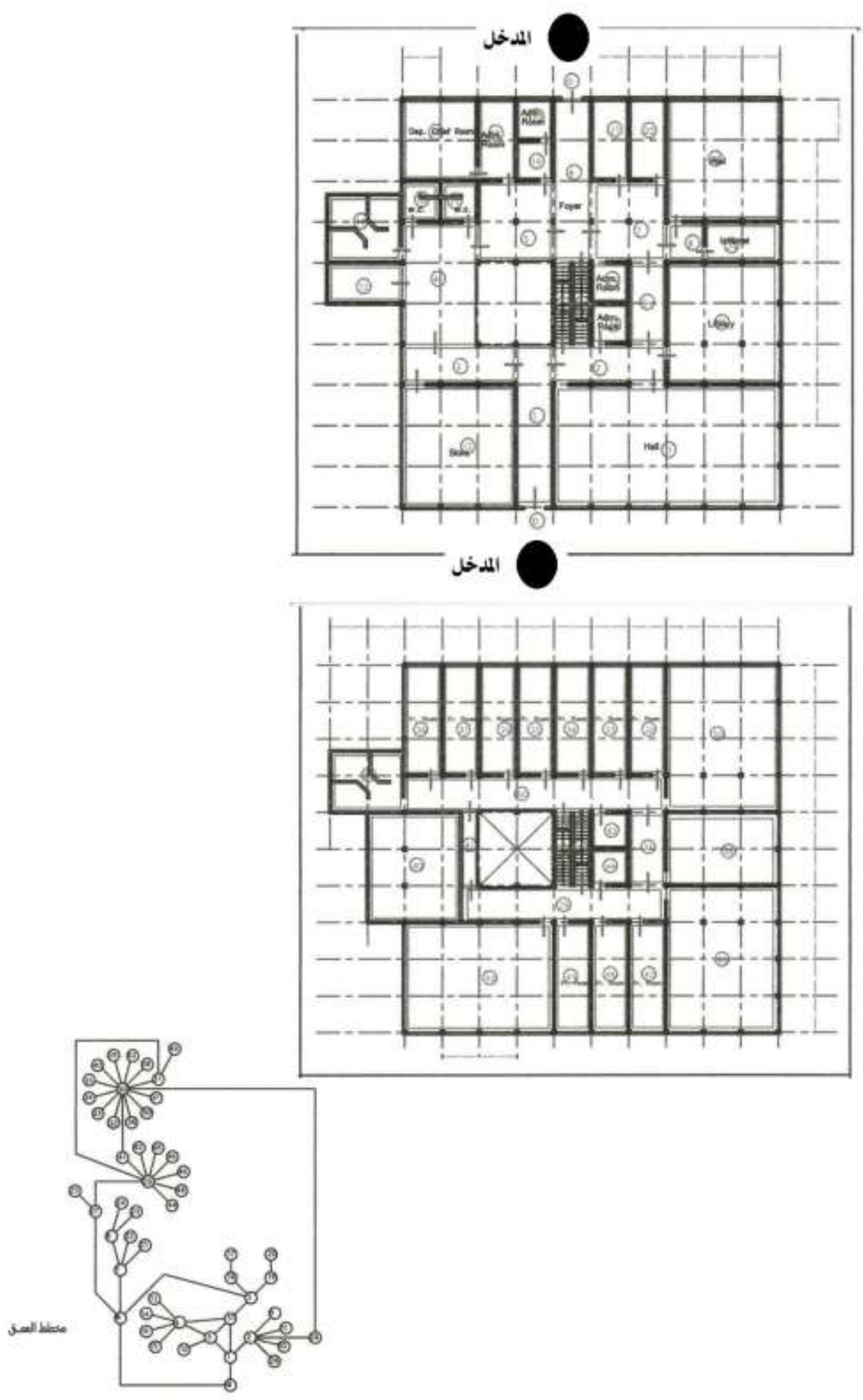

الشكل (4- ب) مخططات قسم علوم الحياة مع المخطط التحدبي ومخطط العمق بعد تغيير المدخل 
No. 3

April 2014
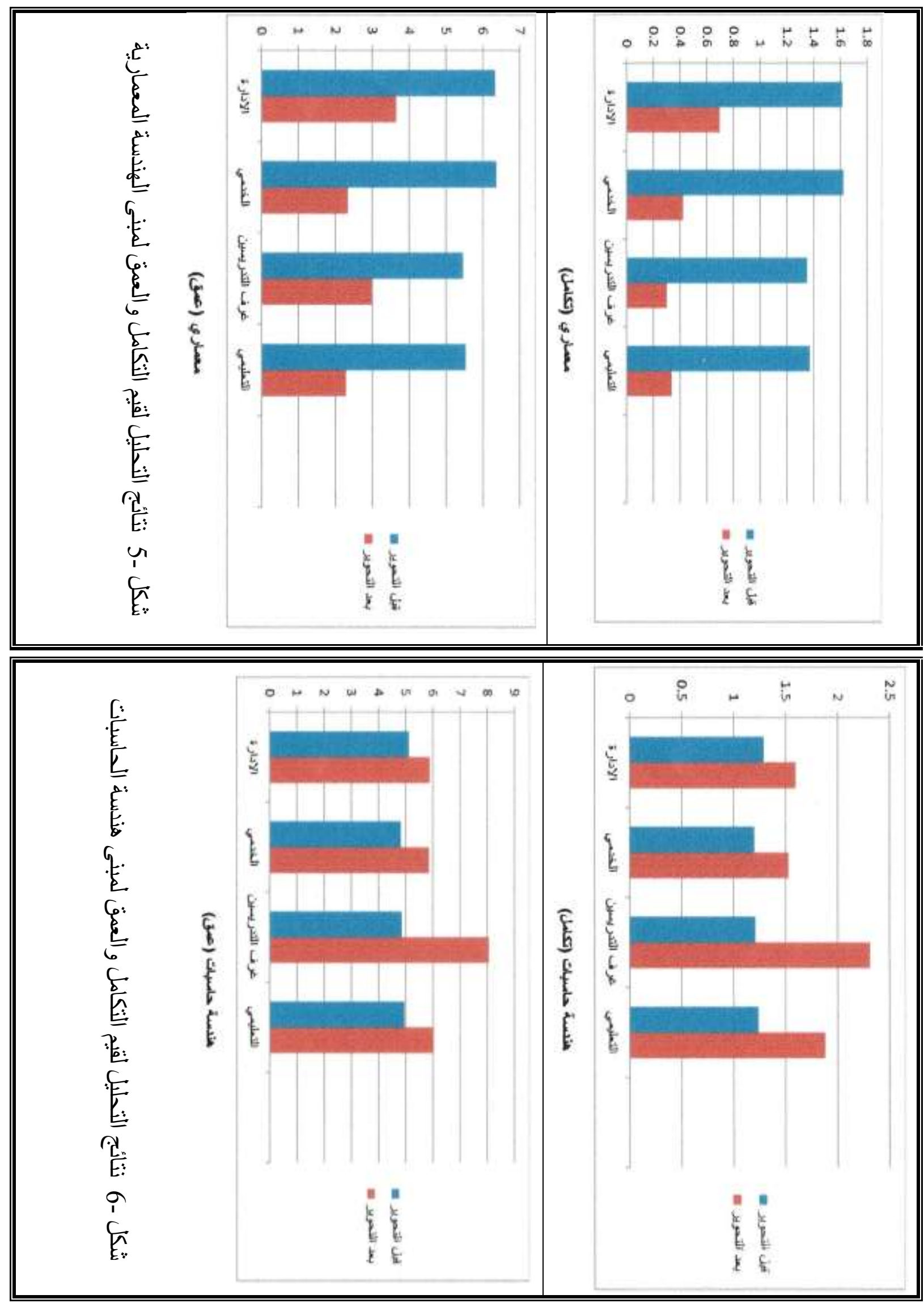
العزاوي: أثر تغير موقع العداخل على خصائص التنظيم الفضائي للمباني التطليمية في جامعة الموصل
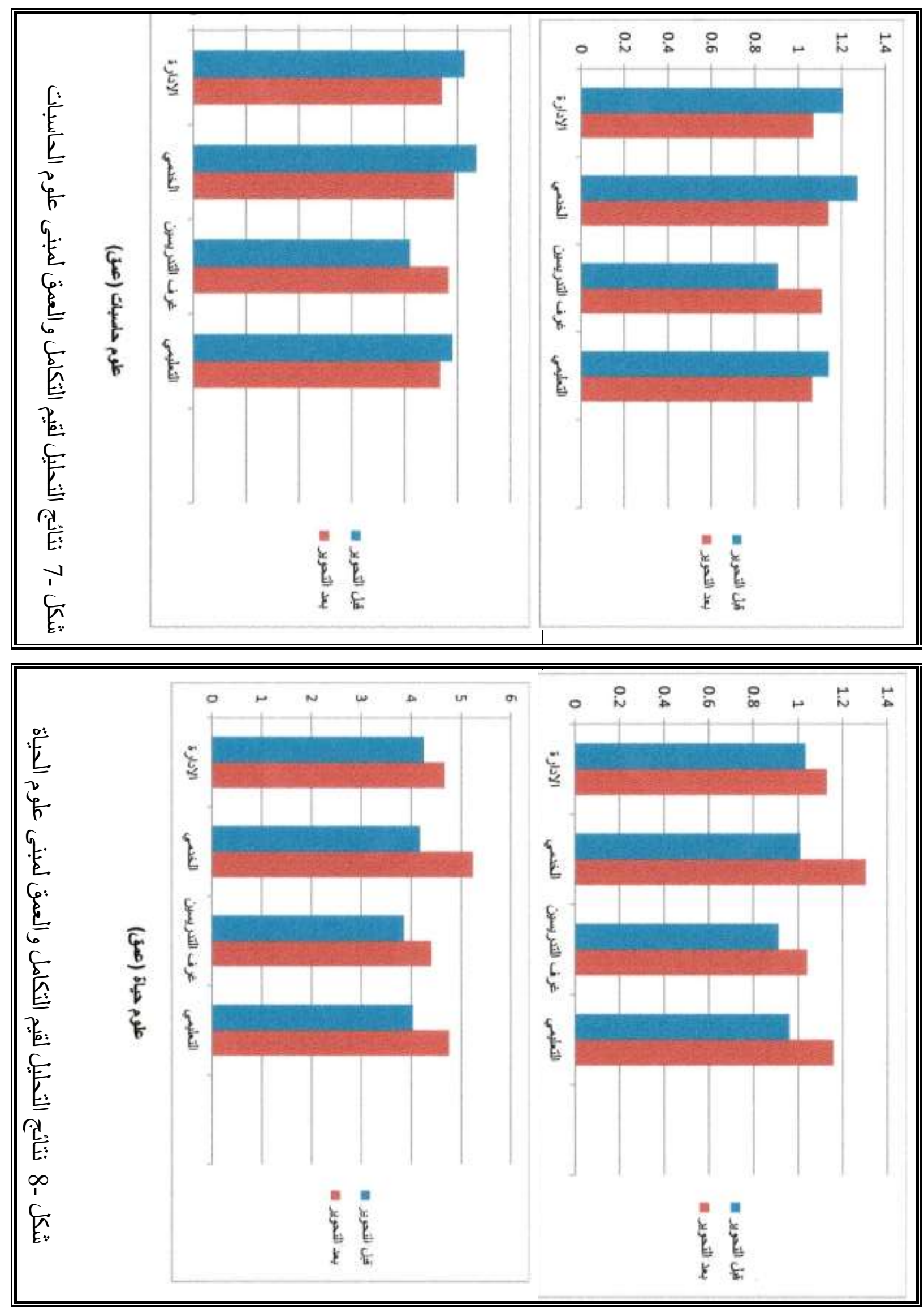
الجمعة، د. أحمد قاسم، "من ذكرياتي عن المركز الجامعي"، في ندوة " التصميم الأساسي لموقع جامعة الموصل-

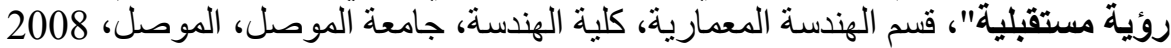

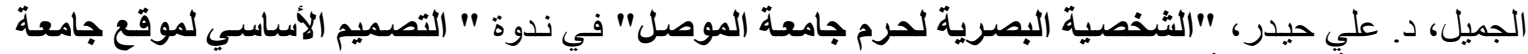

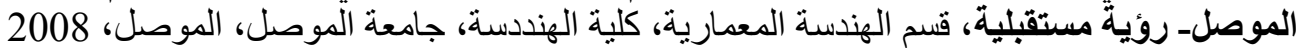

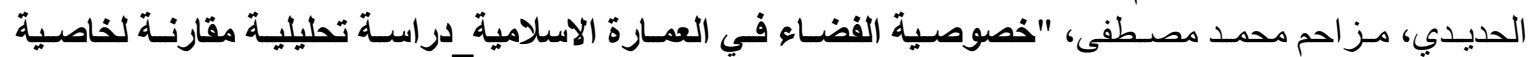

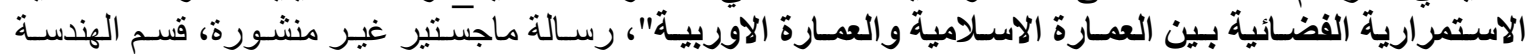

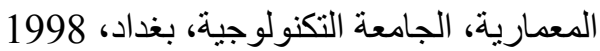

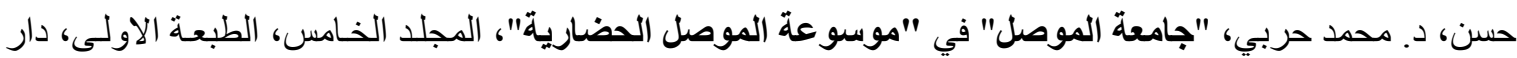

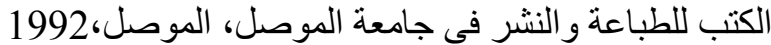

الحيالي، حافظ عبد يحيى أحمد، "تغير العناصر المعمارية وأثره في عمارة الموصل"، رسالة المعالة ماجستير غير منشورة،

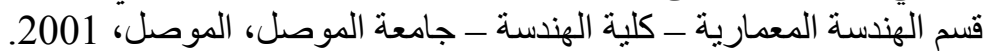

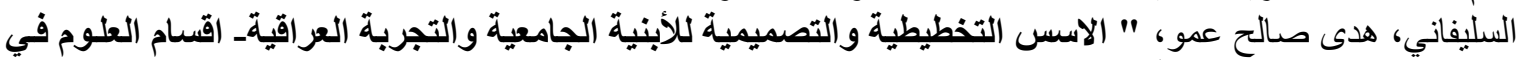

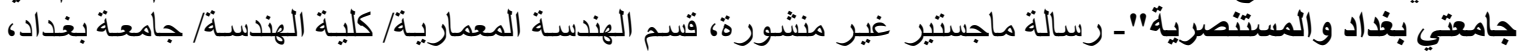
بغداد، 1989 198

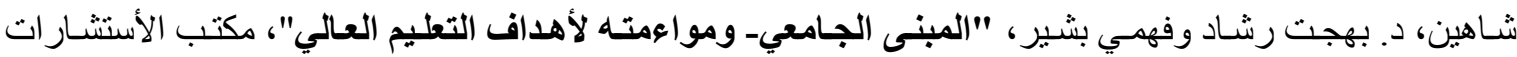

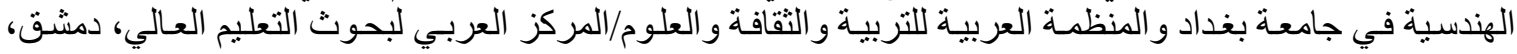
2000

صفو، بيداء حنا، "الاضافات في العمارة"، رسـالة ماجستير غير منشورة، قسم الهندسـة المعماريـة ـ كليـة الهندسـة ـ

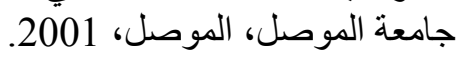

مهذي، سعاد عبد علي وغادة موسى رزوقي، الجي، "أثر تغير البيئة العضرية في خصوصية العمـارة"، وزارة الاسكان و التعمير، الجمهورية العر اقية، بغداد، 1989.

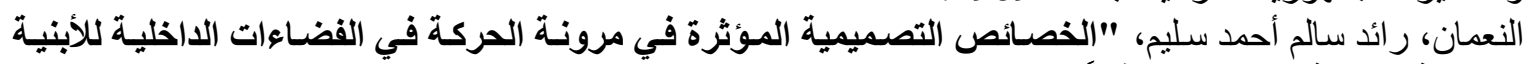

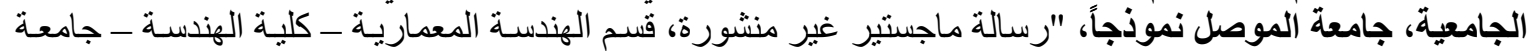
الموصل، الموصل،

- Al-Nijaidi, Hazim, R., "Flexibility in the Design of Buildings", Ph. D. Thesis, Oxford Polytechnic, Oxford, 1985.

- Booklet, Z. - Centre For Excellence in Universal Design, "Building For Everyone Series: A Universal Design Approach - Entrances and Horizontal Circulation" NDA - National Disability Authority, Dublin The series is available online at www.nda.ie and www.universaldesign.ie .

- Ching, Francis D.K. ," Architecture : form , space, and order , $2^{\text {nd }}$ Edition , John wiley sons , INC. New York, 1996.

- Ching, Francis D.K. , " Interior design illustrated ", van Nostrand Reinhold Company, New York, 1987.

- Hillier, Bill, And Hanson, Julienne, The Social Logic of Space , Cambridge University Press, Cambridge, 1984 .

- Hillier, Bill, Space is the Machine, Cambridge University Press, Cambridge. 1996.

- Lang, Holin, "Creating Architectural Theory_ The Role of Behavioral Sciences in Environmental Design, VNR, New York, 1987.

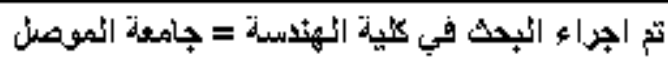

